\title{
ARTICLE Inactivation of TSC1 promotes epithelial-mesenchymal transition of renal tubular epithelial cells in mouse diabetic nephropathy
}

\author{
Qian Lu', Yi-bing Chen ${ }^{1}$, Hao Yang ${ }^{1}$, Wen-wen Wang ${ }^{2}$, Cheng-cheng $\mathrm{Li}^{1}$, Lei Wang ${ }^{1}$, Jin Wang ${ }^{1}$, Lei Du' and Xiao-xing Yin ${ }^{1}$
}

\begin{abstract}
Epithelial-mesenchymal transition (EMT) of renal tubular epithelial cells is one of the potential mechanisms of renal fibrosis, which promotes the development of diabetic nephropathy (DN). However, the molecular mechanisms of EMT remain largely unknown. Tuberous sclerosis proteins TSC1 and TSC2 are key integrators of growth factor signaling, and the loss of TSC1 or TSC2 function leads to a spectrum of diseases that underlie abnormalities in cell growth, proliferation, differentiation, and migration. In this study, we investigated the effects of TSC1 on high glucose (HG)-induced EMT of human proximal tubular epithelial HK-2 cells in vitro and renal fibrosis in $\mathrm{TSC}^{-1-}$ and $d b / d b$ mice. We found that the exposure of HK-2 cells to $\mathrm{HG}$ (30 mM) time-dependently decreased TSC1 expression, increased the phosphorylation of $\mathrm{mTORC1}$, P70S6K, and 4E-BP-1, and promoted cell migration, resulting in EMT. Transfection of the cells with TSC1 mimic significantly ameliorated HG-induced EMT of HK-2 cells. The tubules-specific TSC1 knockout mice $\left(\mathrm{TSC}^{-1-}\right)$ displayed a significant decline in renal function. $\mathrm{TSC}^{-1-}$ mice, similar to $d b / d b$ mice, showed greatly activated mTORC1 signaling and EMT process in the renal cortex and exacerbated renal fibrosis. Overexpression of TSC1 through LV-TSC1 transfection significantly alleviated the progression of EMT and renal fibrosis in the renal cortex of $d b / d b$ mice. Taken together, our results suggest that TSC1 plays a key role in mediating HG-induced EMT, and inhibition of TSC1-regulated mTORC1 signaling may be a potential approach to prevent renal fibrosis in DN.
\end{abstract}

Keywords: diabetic nephropathy; tuberous sclerosis complex 1 ; epithelial-mesenchymal transition; renal fibrosis; human proximal tubular epithelial cell line $\mathrm{HK}-2 ; \mathrm{TSC}^{-1-}$ mice; $d b / d b$ mice; rapamycin

Acta Pharmacologica Sinica (2019) 40:1555-1567; https://doi.org/10.1038/s41401-019-0244-6

\section{INTRODUCTION}

Diabetic nephropathy (DN) is the most common clinical chronic kidney disease and has been clearly underscored as the main cause of end-stage renal disease [1]. The main pathological features of DN are glomerular basement membrane thickening, extracellular matrix (ECM) deposition, and renal interstitial fibrosis. Among these pathogeneses, progressive renal interstitial fibrosis has been identified as the hallmark pathological feature of DN $[2,3]$. Previous studies have indicated that the epithelial-mesenchymal transition (EMT) plays an important role in promoting renal interstitial fibrosis in DN. EMT is a biologic process that allows a polarized epithelial cell to undergo multiple biochemical changes that enable it to acquire a mesenchymal cell phenotype. In this process, epithelial cells enhance migratory capacity and invasiveness, elevate anti-apoptotic ability, and promote ECM deposition [4, 5]. However, the intracellular molecular mechanisms of EMT are not fully understood. Therefore, it is important to elucidate the mechanism of renal tubular EMT in the prevention and treatment of DN.

Tuberous sclerosis complex (TSC) is an autosomal dominant genetic disorder caused by inactivating mutations in the TSC1 or
TSC2 genes, which are associated with benign and, more rarely, malignant tumors [6]. The tuberous sclerosis proteins TSC1 and TSC2 are key integrators of growth factor signaling [7]. TSC1 and TSC2 encode the proteins hamartin and tuberin, respectively, which together form TSC1-TSC2. The loss of TSC1 or TSC2 function leads to a spectrum of diseases that underlie abnormalities in cell growth, proliferation, differentiation, and migration [8]. The TSC1-TSC2 complex is situated at the crossroads of several important signaling pathways and is heavily regulated by phosphorylation. Emerging evidence has demonstrated that Akt, ERKs, and ribosomal S6 kinase inhibit phosphorylation of TSC2 $[9,10]$, and IKB kinase $\beta$ (IKK $\beta$ ) inhibits phosphorylation of TSC1 [11]. However, AMP-activated protein kinase (AMPK), an essential cellular energy sensor, phosphorylates and activates TSC2 [12]. Akt-driven phosphorylation prevents TSC1-TSC2 localization to intracellular membranes. ERKs, on the other hand, are suggested to stimulate the dissociation of the TSC1-TSC2 complex. TSC1-TSC2 negatively regulates activation of the mammalian target of rapamycin (mTOR) pathway via Rheb and suppresses cell growth and proliferation by acting in a heteromeric complex to inhibit mTOR [13].

\footnotetext{
${ }^{1}$ Jiangsu Key Laboratory of New Drug Research and Clinical Pharmacy, Xuzhou Medical University, Xuzhou 221004, China and ${ }^{2}$ Wuxi Higher Health Vocational Technology School, Wuxi 214028, China

Correspondence: Xiao-xing Yin (yinxx@xzhmu.edu.cn)

These authors contributed equally: Qian Lu, Yi-bing Chen.
}

Received: 14 October 2018 Accepted: 25 April 2019

Published online: 24 June 2019 
Recently, TSC1 and TSC2 were confirmed to play a critical role in the development and progression of EMT in multiple tumor cells. TSC1 interacts with the transforming growth factor- $\beta$ (TGF- $\beta$ ) receptor complex and Smad2/3 and regulates Smad2/3 phosphorylation and target gene expression, which controls TGF- $\beta$-induced growth arrest and EMT in HeLa cells. Interestingly, TSC1 functions independently of TSC2 [14]. Cells deficient in TSC2 significantly reduce the expression of $\mathrm{E}$-cadherin via the $\mathrm{Akt} / \mathrm{mTORC} 1$ pathway, resulting in cells that are less adhesive, more prone to detachment, and undergo EMT in human renal angiomyolipomas and lymphangioleiomyomatosis [15].

Despite the extensive biochemical and molecular characterizations of the TSC1-TSC2 pathway in tumors, the mechanisms linking these findings to DN remain, however, not quite understood. Recent experimental evidence suggested that the basal levels of phospho-tuberin and fibronectin expression were significantly increased in the kidney cortex of $\mathrm{TSC2}^{+/-}$rats, which promoted renal interstitial fibrosis in diabetes [16]. Furthermore, podocyte-specific TSC1 knockout mice exhibited significant glomerular hypertrophy and mesangial expansion with pathologic accumulation of ECM [17]. Overall, the above findings clearly established that TSC1 and TSC2 are involved in a variety of physiological and pathological processes in DN. However, the role of TSC1 in the EMT of diabetes-induced renal tubular epithelial cells and renal fibrosis has not been fully demonstrated.

In the present study, we investigated the potential role of TSC1 in the EMT of renal tubular epithelial cells, renal fibrosis in HGinduced HK-2 cells, and proximal tubule-specific TSC1 knockout mice to illuminate the possible mechanisms underlying these effects. The above descriptions could provide evidence that TSC1 could be a fundamental novel target for renal fibrosis in DN.

\section{MATERIALS AND METHODS}

\section{Cell culture and treatment}

The human proximal tubular epithelial cell line HK-2 was purchased from American Type Culture Collection (Manassas, VA, USA). The cells were cultured in Gibco BASIC RPMI-1640 medium containing $11.1 \mathrm{mM} d$-glucose, supplemented with $10 \%$ fetal bovine serum (ExCell Biology, Shanghai, China), $100 \mathrm{U} / \mathrm{mL}$ penicillin, and $100 \mu \mathrm{g} / \mathrm{mL}$ streptomycin at $37^{\circ} \mathrm{C}$ in a humid atmosphere with $5 \% \mathrm{CO}_{2}$. The cells were passaged when the cells were $80 \%-90 \%$ confluent. The confluent cells were growtharrested for $24 \mathrm{~h}$ in serum-free Dulbecco's modified Eagle's medium containing $5.56 \mathrm{mM} d$-glucose (normal glucose, NG) before the experiments. To induce the EMT model, the cells were cultured in high glucose (HG) medium containing $30 \mathrm{mM} d$ glucose for $72 \mathrm{~h}$. Rapamycin (Cell Signaling Technology, Beverly, MA, USA) was added to the medium at a concentration of $20 \mathrm{nM}$.

\section{Gene transfection}

Transfection reagents were purchased from Gene Pharma Company (Shanghai, China). The lentiviral vectors containing the stem loop sequences of short hairpin RNA (shRNA) specifically targeting human and mice TSC1 were designed and produced by GeneChem (Shanghai, China). Cells were cultured in 60-mm Petri dishes and grown to $40 \%-50 \%$ confluency without antibiotics. The transfection of plasmids $(6 \mu \mathrm{g})$ was carried out using Lipofectamine 3000 Transfection Reagent (Invitrogen, USA) according to the manufacturer's instructions. The ratio of plasmids $(\mu \mathrm{g})$ and transfection reagents $(\mu \mathrm{L})$ was 3:4. The cells were harvested $48 \mathrm{~h}$ after transfection.

Wound-healing assay

Plate lines on six-well plates were made, marked with pen, and drawn at a level in the middle of each hole; cells $\left(2.0 \times 10^{5}\right.$ cells/ well) in the six-well plates then grew to $90 \%$ confluence, after which the culturing medium was discarded, and cells were washed with phosphate-buffered saline (PBS) twice. Lines on the surface of the monolayer cell (perpendicular to the basement of the plate) were drawn using a $100 \mu \mathrm{L}$ sterile plastic gun head. Furthermore, cell debris and detached cells were carefully washed off. Micrographs of the cell migration state $(0 \mathrm{~h})$ and the corresponding treatment factors were obtained. After $24 \mathrm{~h}$ of incubation, marked changes consequent to cellular repair were observed under a phase-contrast microscope. The micrograph was also obtained at a defined magnification $(\times 10)$.

Animals

The tubule-specific TSC1 knockout mice with mixed genetic backgrounds were generated by crossbreeding TSC1-floxed mice (Stock No: 005680; Jackson Laboratory, Bar Harbor, ME) with KspCre transgenic mice (Stock No: 008781; Jackson Laboratory). By mating TSC1-floxed mice with Ksp-Cre transgenic mice, mice that were heterozygous for the TSC1-floxed allele were generated (genotype: $\mathrm{TSC}_{1}{ }^{\mathrm{f} / \mathrm{wt}}, \mathrm{Cre}^{+/-}$). These mice were bred with $\mathrm{TSC} 1^{\mathrm{f} / \mathrm{fl}}$ to inactivate both TSC1 alleles by Cre-mediated excision, thereby creating conditional knockout mice in which the TSC1 gene was specifically disrupted in tubules (genotype: $\mathrm{TSC}^{\mathrm{fl} / \mathrm{fl}}, \mathrm{Cre}^{+/-}$). The breeding protocol also generated heterozygous littermates (genotype: $\mathrm{TSC}^{\mathrm{f} / \mathrm{wt}}, \mathrm{Cre}^{+/-}$) and several groups with different genotypes $\left(\mathrm{TSC}^{\mathrm{fl} / \mathrm{fl}}, \mathrm{Cre}^{-/-} ; \mathrm{TSC}^{\mathrm{fl} / \mathrm{wt}}\right)$. Littermates with genotype $\mathrm{TSC}^{\mathrm{fl} / \mathrm{fl}}, \mathrm{Cre}^{-/-}$and $\mathrm{TSC} 1^{\text {wt/wt }}, \mathrm{Cre}^{+/-}$were used as controls throughout the experiments. PCR-based analysis of the genomic DNA was used to ascertain the genotype of the mice. All male animals were housed in pathogen-free conditions with ad libitum access to food and water at the Jiangsu Key Laboratory of New Drug Research and Clinical Pharmacy. For pharmacologic treatment, knockout mice were treated with rapamycin at the age of 2 months. Rapamycin was dissolved in 5\% dimethyl sulfoxide (DMSO) and injected intraperitoneally (i.p.) daily at $2.5 \mathrm{mg} / \mathrm{kg}$ body weight for 2 months. The control group received an equal volume of $5 \%$ DMSO solution at the same time. After 8 weeks, all the mice were placed in metabolic cages for urine collection, and blood samples were also collected. When the mice were sacrificed, the kidneys were rapidly excised, collected, and rinsed with a precooled saline solution. Part of the kidney tissues were fixed with 4\% paraformaldehyde and embedded in paraffin, while the remaining tissues were immediately frozen in liquid nitrogen for $2 \mathrm{~h}$ and stored at $-80^{\circ} \mathrm{C}$ for biochemical analysis.

Lentiviral vector with TSC1 protein (LV-TSC1) was chosen for overexpressing TSC1 gene expression, and lentiviral empty vector (LV) was used as the control. Male C57BLKS/J $d b / d b$ and $d b / m$ mice ( 8 weeks old) were used in this study, which were obtained from the Nanjing Biomedical Research Institute of Nanjing University (Nanjing, China). The $d b / m$ mice were selected as the control group $(d b / m, n=8)$. The $d b / d b$ mice were randomly divided into two groups as follows: lentiviral empty vectortransinfected $d b / d b$ group $(d b / d b$-LV, $n=8)$ and LV-TSC1transinfected $d b / d b$ group (LV-TSC1, $n=8$ ). Both LV-TSC1 and LV control were diluted to a total volume of $300 \mu \mathrm{L}$ containing $6 \times 10^{7}$ TU. At the age of 12 weeks, $16 \mathrm{db} / \mathrm{db}$ mice were transinfected with lentiviral empty vector or LV-TSC1 by tail vein injection once a week for 4 weeks [18]. The animals were housed in the accredited mouse barrier facility at the Jiangsu Key Laboratory of New Drug Research and Clinical Pharmacy with access to standard chow and water ad libitum before and during the experiments. At the end of the intervention, blood glucose levels and urinary protein in all of the mice were measured. The perfused kidneys were dissected and kept at $-80^{\circ} \mathrm{C}$ until further analysis. The transfection efficiency of TSC1 was measured by Western blotting.

Measurement of renal function and biochemical parameters Blood glucose levels were measured by test strips (Johnson, CA, USA). To assess renal function, biomarkers, such as blood urea nitrogen (BUN) and blood creatinine $(\mathrm{Cr})$, were measured by $\mathrm{Cr}$ 
and BUN Assay Kits (Jiancheng Bioengineering Institute, Nanjing, China). The values for urine microalbuminuria (mAlb) were evaluated using the Urine Albumin Kit (Guduo Biological, Shanghai, China). Kidney weight index $(\mathrm{mg} / \mathrm{g})$ was the ratio of the weight of the two kidneys and the body weight of a mouse. All the experiments were conducted according to the manufacturer's protocol.

Quantitative real-time reverse transcription-PCR

Total RNA from the kidney cortex and HK-2 cells was extracted according to the manufacturer's protocol using TRIzol reagent (Invitrogen, Carlsbad, CA, USA) and then synthesized to CDNA using the RT-ReverTra Ace qPCR RT Kit (Toyobo, Osaka, Japan). Gene expression was measured as previously described [19]. LightCycler 480 software (version 1.5; Roche Applied Science, Mannheim, Germany) was used to analyze the results. Relative mRNA levels were analyzed using the $\Delta \Delta C t$ method. Primers (Table 1) were purchased from Sangon Biotech (Shanghai, China).

Kidney histology and immunohistochemistry analysis

The kidney samples were fixed with $4 \%$ paraformaldehyde and embedded with paraffin. Samples were then prepared at a thickness of $4 \mu \mathrm{m}$ for morphometric and immunohistochemistry analyses. For immunohistochemistry, the paraffin-embedded kidney sections were deparaffinized in dimethyl benzene, hydrated in graded ethanol, and immersed in 3\% hydrogen peroxide to quench endogenous peroxidase activity. Sequentially, these samples were blocked with normal goat serum and incubated with primary antibodies against laminin and collagen type IV (Abcam, Cambridge, UK) antibodies overnight at $4^{\circ} \mathrm{C}$. Then, the sections were stained using a polymer HRP detection system (ZSGB-BIO, Beijing, China) and counterstained with hematoxylin. Sirius Red and Masson staining were used to evaluate the localization and deposition of collagen. Three nonoverlapping renal interstitial fields of each section were observed under an Olympus BX43F microscope. The area of staining was measured using an image analysis system (Image-Pro Plus 4.0; Media Cybernetics, Silver Spring, MD).

Western blot analysis

HK-2 cells and homogenates from the renal cortex were prepared using lysates by RIPA lysis buffer containing protease inhibitor 1 $\mathrm{mM}$ PMSF, $1 \mathrm{mM} \mathrm{Na}_{3} \mathrm{VO}_{4}$, and $20 \mathrm{mM} \mathrm{NaF}$ on ice. The lysates were collected after centrifugation at $12000 \mathrm{rev} / \mathrm{min}$ at $4{ }^{\circ} \mathrm{C}$ for $15 \mathrm{~min}$. Protein concentrations were tested with the bicinchoninic acid (BCA) Protein Assay Kit (Pierce Thermo-Scientific, Rockford, IL, USA) according to the manufacturer's instructions. These protein samples were loaded and separated by $12 \%$ SDS-PAGE and electroblotted to nitrocellulose membranes (Millipore, USA). The membranes were blocked with $3 \%$ bovine serum albumin in PBS at room temperature for $1 \mathrm{~h}$ and incubated overnight at $4{ }^{\circ} \mathrm{C}$ with the primary antibodies against mTORC1, phosphor-mTORC1 (Ser2448), p70S6K, phospho-p70S6K (Thr389), E-cadherin, ZO-1, Vimentin, and Snail, which were obtained from Cell Signaling Technology (Beverly, MA, USA). a-SMA, Twist, and Snail antibodies were purchased from Abcam (Cambridge, UK), and $\beta$-actin antibody was obtained from Bioworld Technology (St. Louis, USA). Following three washes with PBST, the membranes were incubated with IRDye $800 \mathrm{CW}$ secondary antibodies (LI-COR, USA) in the dark for $1 \mathrm{~h}$, and specific bands were visualized by the Odyssey Sa 700, 800 system (LI-COR, USA). The results were normalized to $\beta$-actin and quantified with image analysis systems (National Institutes of Health, Bethesda, MD, USA).

\section{Statistical analysis}

All data are presented as the means \pm SEM. The group comparisons were achieved using one-way ANOVA, followed by the Newman-Keuls test. Statistical significance was considered at $P<$ 0.05 . The statistical analysis was performed using SPSS statistical software (Version 16.0).

\section{RESULTS}

Effect of HG on TSC1 signaling in HK-2 cells

HK-2 cells were exposed to HG solution ( $30 \mathrm{mM} d$-glucose) for 24, 48, and $72 \mathrm{~h}$, and TSC1 expression and downstream molecule phosphorylation with HG stimulation were detected by Western blotting. As shown in Fig. 1, there were no significant changes in the expression of TSC1, p-mTORC1, p-70S6K, and p-4E-BP1 in HK-2 cells after $24 \mathrm{~h}$. However, exposure of HK-2 cells to HG solution for $72 \mathrm{~h}$ significantly decreased the expression of TSC1 in the HG group compared with that in the NG group. In contrast, the phosphorylation rate of mTORC1 (Ser2448) and its downstream effector proteins, p-70S6K (Thr389) and p-4E-BP1 (Ser65), were significantly increased in HG-induced HK-2 cells. The results suggested that HG could inhibit the expression of TSC1, resulting in activation of the downstream signaling pathway.

Effect of TSC1 activation on HG-induced EMT in HK-2 cells EMT of tubular epithelial cells is the leading cause of kidney fibrosis. To investigate whether the regulation of EMT is induced by the TSC1/mTORC1 pathway, we observed morphological changes under an inverted microscope. The cells in the HG and TSC1 vehicle groups lost their pebbled epithelial appearance and obtained a spindle-shaped fibrous shape compared with cells in the normal group. In addition, compared with the HG group,

\begin{tabular}{|c|c|c|c|}
\hline Snail & Homo sapiens & Forward: CCCAATCGGAAGCCTAACTA & $65 \mathrm{bp}$ \\
\hline \multirow[t]{2}{*}{ Snail } & Mus musculus & Forward: TGGCTGATGGAGTGCCTTTG & $115 \mathrm{bp}$ \\
\hline & & Reverse: AGCCAGTGGGTTGGCTTTAG & \\
\hline \multirow[t]{2}{*}{ Twist } & Mus musculus & Forward: CTTGCCAATCAGCCACTGAC & $216 \mathrm{bp}$ \\
\hline & & Reverse: CCAGTTTGATCCCAGCGTTT & \\
\hline \multirow[t]{2}{*}{$\beta$-Actin } & Homo sapiens & Forward: GCAAAGACCTGTACGCCAAC & $144 \mathrm{bp}$ \\
\hline & & Reverse: AGTACTTGCGCTCAGGAGGA & \\
\hline$\beta$-Actin & Mus musculus & Forward: AGAGGGAAATCGTGCGTGAC & $138 \mathrm{bp}$ \\
\hline
\end{tabular}



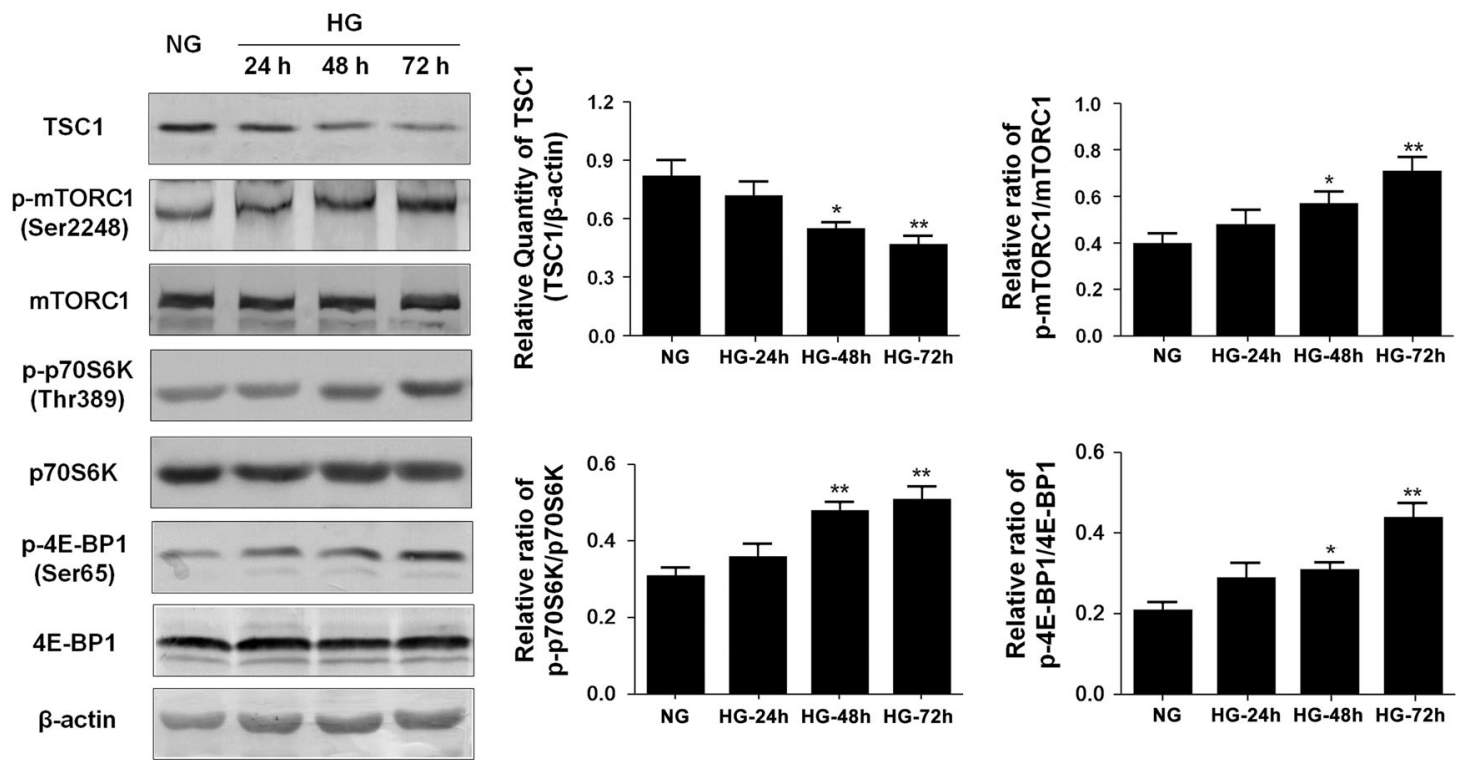

Fig. 1 The time course change of TSC1 expression and downstream molecules phosphorylation with high-glucose stimulation. Data are presented as the mean $\pm \mathrm{SEM}, n=3 .{ }^{*} P<0.05,{ }^{* *} P<0.01$, compared with NG

a
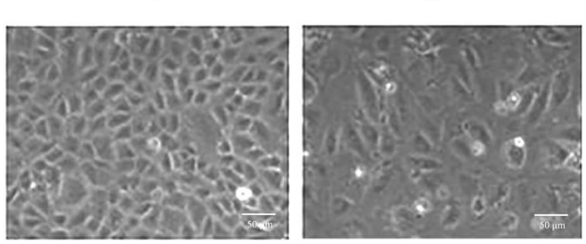

b

\begin{tabular}{|c|c|c|}
\hline NG & + & - \\
\hline HG & - & + \\
\hline sc1 Vehicle & - & - \\
\hline SC1 mimic & - & - \\
\hline Rapamycin & - & - \\
\hline
\end{tabular}

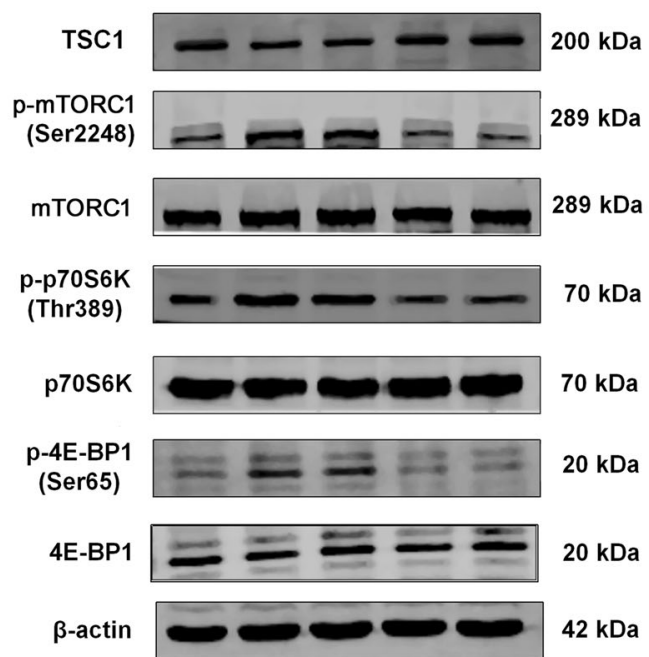

HG+TSC1 Vehicle HG+TSC1 mimic
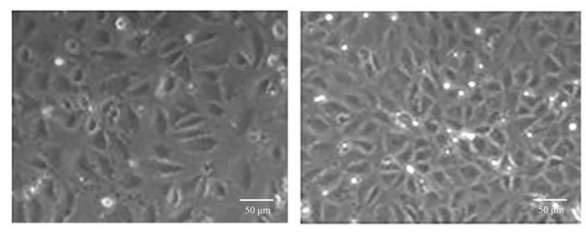

HG+Rapamycin

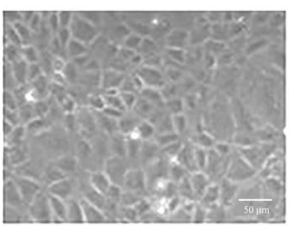

C
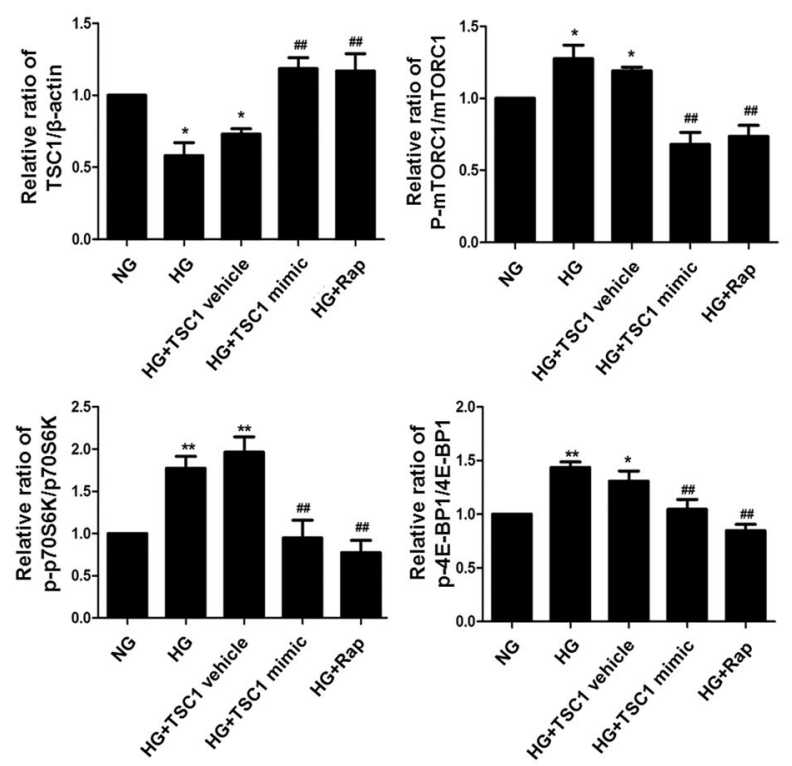

Fig. 2 Effect of high glucose on TSC1 signaling in HK-2 cells. a Effects of HG, TSC1, and rapamycin stimulation on the changes of HK-2 cells morphology (magnification, $\times 400$ ). b The expression of TSC1, mTOR, p70S6K, and 4E-BP1 in HK-2 cells through Western blotting. c Statistical analysis of TSC1 expression and relative phosphorylation levels of mTOR, p70S6K, and 4E-BP1 in HK-2 cells. NG: cells treated with normal glucose $5.56 \mathrm{mM}$; HG: cells treated with high glucose $30 \mathrm{mM}$; HG+TSC1 vehicle: cells treated with high glucose +TSC1 vehicle plasmids for 48 h; HG+TSC1 mimic: cells treated with high glucose +TSC1 mimic plasmids for $48 \mathrm{~h}$. HG+Rap: cells treated with high glucose $+20 \mathrm{nM}$ rapamycin. Cells were starved for $24 \mathrm{~h}$ and treated with normal glucose, high glucose and rapamycin for $72 \mathrm{~h}$. Data are presented as the mean $\pm \mathrm{SEM}, n=3 .{ }^{*} P<0.05,{ }^{* *} P<0.01$, compared with NG; ${ }^{\#} P<0.05$, ${ }^{\# \#} P<0.01$, compared with $\mathrm{HG}$. Bar $=50 \mu \mathrm{m}$ 
transfection with TSC1 mimic and treatment with rapamycin prevented morphological changes (Fig. 2a). To further evaluate the roles of TSC1 in the downstream pathway in HK-2 cells, the expression of mTORC1, p70S6K, and 4-EB-P1 in HG was detected. As shown in Fig. 2b, c, cells transfected with the TSC1 vehicle did not affect this phenomenon under HG conditions, while transfection with TSC1 mimic significantly overexpressed the TSC1 protein. With the increase of TSC1 expression, phosphorylation of mTORC1, p70S6K, and 4E-BP1 were significantly inhibited in HGinduced HK-2 cells. Rapamycin, a specific inhibitor of mTORC1, significantly inhibited mTORC1, p70S6K, and 4E-BP1 phosphorylation in HK-2 cells. In conclusion, these results indicate that HG could inhibit TSC1 and promote the activation of the mTORC1 pathway in HK-2 cells.

Because EMT is associated with enhanced cellular motility, we evaluated the effects of TSC1 on the migration of HK-2 cells under HG conditions by a wound-healing assay. We found that the rate of wound closure of HK-2 cells increased significantly in the HG groups when compared with the NG group. However, cell migration was significantly reduced after TSC1 mimic transfection (overexpression). Similarly, we also noticed that rapamycin could also decrease the cell migration rate (Fig. 3a).

To further confirm whether the regulation of EMT is induced by the TSC1 signaling pathway, the EMT biomarker proteins (epithelial markers: ZO-1 and E-cadherin; mesenchymal markers: Vimentin and a-SMA) were examined by Western blotting in HGinduced HK-2 cells. ZO-1 and E-cadherin were significantly downregulated in HG-induced HK-2 cells, while Vimentin and aSMA were significantly upregulated compared to control conditions in HK-2 cells. Transfection with the TSC1 mimic notably increased the expression of ZO-1 and E-cadherin, while the expression of Vimentin and a-SMA were notably decreased compared to the controls. Rapamycin also alleviated the EMT process by upregulating ZO-1 and E-cadherin expression and downregulating Vimentin and a-SMA expression (Fig. 3b, c). ZO-1 was found to be prominently localized at the cell-cell junctions in cells cultured in NG, but this distribution was largely lost in HGcultured HK-2 cells. Treatment of these cells with TSC1 mimic and rapamycin caused reformation of the cell-cell junctions and decreased expression of a-SMA in the cytoplasm when compared to the HG group (Fig. 4).

The transcriptional inhibitors of E-cadherin (Snail and Twist) execute their effect by binding to the promoter E-box region of Ecadherin. The protein expression and mRNA levels of Snail and Twist were detected by Western blotting and quantitative reverse transcription (RT)-PCR analyses. The results showed that HG could increase protein expression and mRNA levels of Snail and Twist in HK-2 cells, while after TSC1 mimic transfection, protein expression and mRNA levels of Snail and Twist significantly decreased (Fig. 3d-f).

Thus, the results of these experiments suggested that TSC1 activation ameliorated EMT progression through the inhibition of the mTORC1 pathway and exhibited a significant reduction in cell migration.

Effects of TSC1 inactivation on EMT in NG-cultured HK-2 cells As previously mentioned, we have demonstrated that TSC1 signaling is inactivated in HG-cultured HK-2 cells, which promote renal tubular EMT. To further investigate whether the regulation of EMT was induced by TSC1, we used the TSC1 shRNA plasmid to construct a TSC1 gene knockdown cell model. We transfected TSC1 shRNA plasmids with NG concentrations, and then morphological changes were observed. Phosphorylation levels of mTORC1, p70S6K, and 4E-BP1 in HK-2 cells were detected by Western blotting. Compared with the vehicle group, the cells in the TSC1 shRNA group exhibited a spindle-shaped fibrous shape and TSC1 expression was decreased, while the phosphorylation rates of $\mathrm{mTORC1}, \mathrm{P} 70 \mathrm{~S} 6 \mathrm{~K}$, and $4 \mathrm{E}-\mathrm{BP} 1$ were elevated in the
TSC1 shRNA group (Fig. 5). These results indicated that TSC1 silencing could activate mTORC1 signaling under NG conditions.

Furthermore, the effect of TSC1 on cell migration was observed by the wound-healing assay. As shown in Fig. 6a, when the TSC1 shRNA plasmid was used to silence TSC1, the cell migration rate was significantly increased. On this basis, we also examined the effect of TSC1 signaling on EMT marker proteins in normal cultured HK-2 cells. Compared with the vehicle group, the expression of ZO-1 and E-cadherin were significantly decreased, while the expression of Vimentin and a-SMA were notably increased in the TSC1 shRNA group (Fig. $6 \mathrm{~b}, \mathrm{~d}$ ). In addition, the expression of Snail and Twist protein and mRNA levels were examined in this study. The expression of two transcription factors and mRNA levels was increased after silencing TSC1 compared with the vehicle group (Fig. 6c). These results indicated that silencing TSC1 activated mTORC1 signaling, resulting in upregulation of Snail and Twist and further promoting the migration ability of HK-2 cells.

Effects of TSC1 on renal function and renal fibrosis of $\mathrm{TSC}^{-/-}$and $\mathrm{db} / \mathrm{db}$ mice

We used the Cre-Loxp system to knockout tubule TSC1 (Fig. 7a) and identified the genotype of the mice by PCR. The mice with Cre-positive and only one TSC1-positive electrophoresis strip at $230 \mathrm{bp}$ were targeted knockout mice (Fig. 7b). After the mice were sacrificed, the knockout of the TSC1 gene in the renal tubules was determined by immunofluorescence. Compared with the control group, the expression of TSC1 in the renal tubules was not expressed in the $\mathrm{TSC}^{-/-}$and $\mathrm{TSC}^{-/-}$with rapamycin treatment groups (Fig. 7c), indicating that the TSC1 knockout mouse model was constructed successfully.

Creatinine $(\mathrm{Cr})$, urea nitrogen $(\mathrm{BUN})$, urinary microalbumin (mAlb), and kidney weight index are important indicators of renal function. $\mathrm{TSC}^{-1-}$ mice were intraperitoneally injected with 2.5 $\mathrm{mg} / \mathrm{kg}$ rapamycin for 8 weeks, after which the kidney weight index and $\mathrm{Cr}$, BUN, and urinary microalbumin levels were detected in each group. As shown in Table 1, compared with the control groups ( $\mathrm{TSC}^{\mathrm{f} / \mathrm{fl}}, \mathrm{Cre}^{-/-}$and $\mathrm{TSC} 1^{\mathrm{wt} / \mathrm{wt}}, \mathrm{Cre}^{+/-}$), the weight of $\mathrm{TSC}^{-1-}$ mice was notably decreased, while the kidney weight index and the $\mathrm{Cr}, \mathrm{BUN}$, and total mAlb levels were significantly increased, suggesting that TSC $1^{-1-}$ mice exhibited renal dysfunction. Compared with $\mathrm{TSC}^{-1-}$ mice, rapamycin improved renal function of $\mathrm{TSC}^{-/-}$mice by reducing kidney weight index, $\mathrm{Cr}$, BUN, and total mAlb. Furthermore, to investigate the effect of TSC1 on renal fibrosis in DN, $d b / d b$ mice were transinfected with lentiviral vector with TSC1 by tail vein injection. We examined the renal function levels of the $d b / \mathrm{m}$ mice and $d b / d b$ mice. Compared with $d b / m$ mice, the levels of $\mathrm{Cr}$, BUN, and total mAlb in the $d b / d b$ mice were notably elevated (Table 2 ). However, treatment with TSC1 ameliorated the renal function levels of $d b / d b$ mice. Taken together, these results suggest that TSC1 plays an important role in renal function in DN.

To further assess the effect of TSC1 on renal fibrosis in mice, collagen accumulation in the renal interstitium was examined by Masson staining. Similar to $d b / d b$ mice, the distribution of Massonpositive areas was significantly increased in the renal cortex of $\mathrm{TSC}^{-1-}$ mice compared with normal controls $\left(\mathrm{TSC} 1^{\mathrm{fl} / \mathrm{fl}}, \mathrm{Cre}^{-/-}\right.$ and $\left.\mathrm{TSC}_{1}{ }^{\mathrm{wt} / \mathrm{wt}}, \mathrm{Cre}^{+/-}\right)$. Additionally, kidney fibrosis was exacerbated in $\mathrm{TSC}^{-1-}$ mice compared with normal controls, as detected by Sirius Red staining. Compared with $\mathrm{TSC}^{-1-}$ mice, treatment with rapamycin significantly reduced collagen deposition. Furthermore, compared with $d b / d b$ mice, overexpression of TSC1 significantly decreased the distribution of Masson-positive areas and Sirius Red-positive areas (Fig. 8a, b). In summary, these data suggested that TSC1 inhibition could promote renal interstitial fibrosis in DN.

Type IV collagen and laminin are important components of the ECM. Animals in the TSC $1^{-1-}$ mice group showed higher 


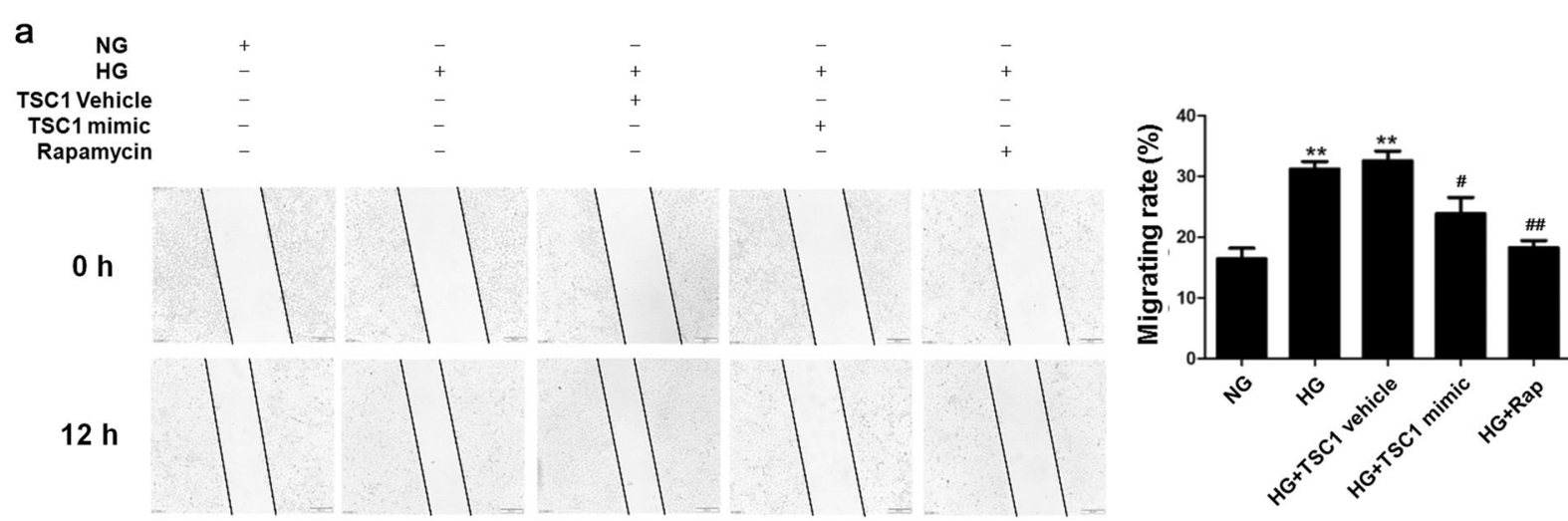

b

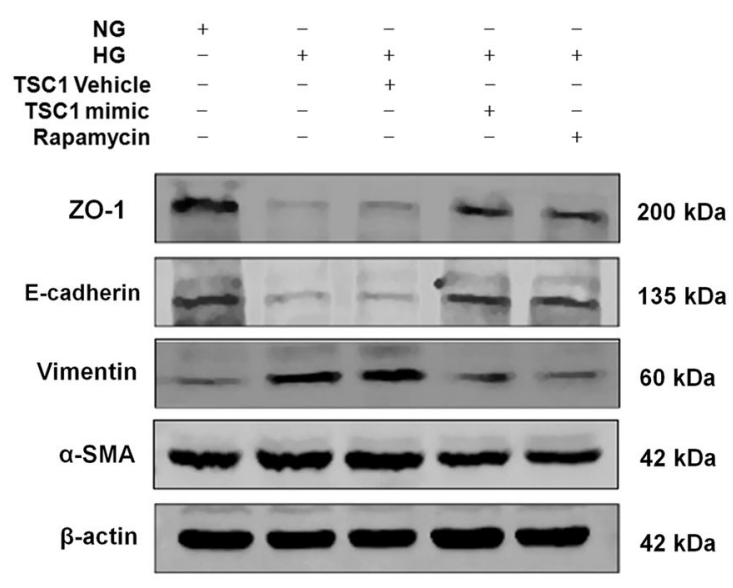

d

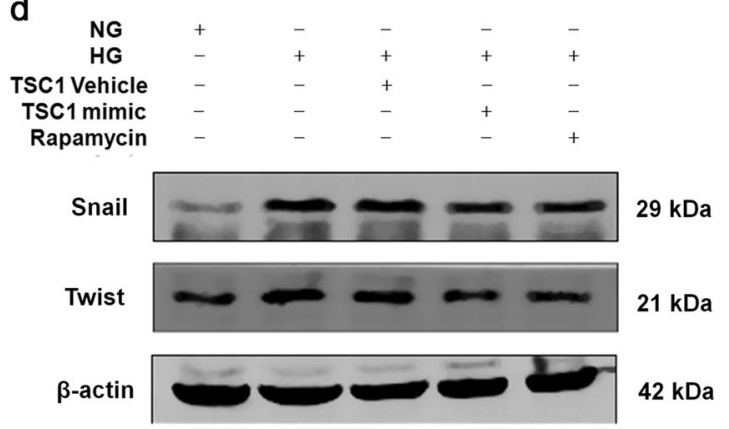

C
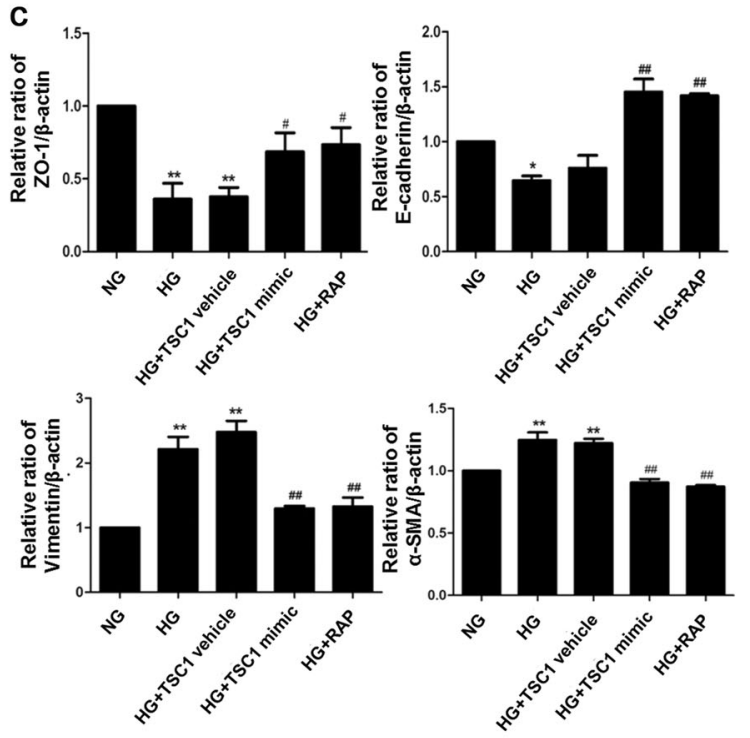

e
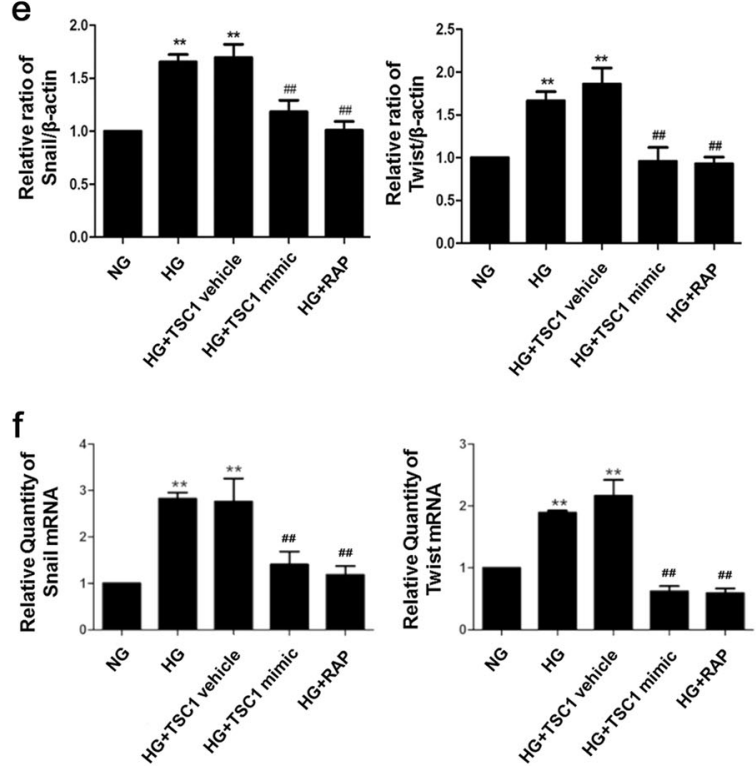

Fig. 3 Effect of TSC signaling activation on high glucose-induced EMT in HK-2 cells. a Longer invaded distances in HK-2 cells transfected with TSC1 mimic plasmids and treated with rapamycin by wound-healing assay. $\mathbf{b}, \mathbf{c}$ Expression of ZO-1, E-cadherin, vimentin, $\alpha-S M A$ in HK-2 cells. d, e Expression of snail and twist in HK-2 cells. $f$ The mRNA levels of snail and twist in high glucose-cultured HK-2 cells by qRT-PCR. Data are presented as the mean $\pm \mathrm{SEM}, n=3 .{ }^{*} P<0.05,{ }^{* *} P<0.01$, compared with NG; ${ }^{\#} P<0.05,{ }^{\# \#} P<0.01$, compared with HG 

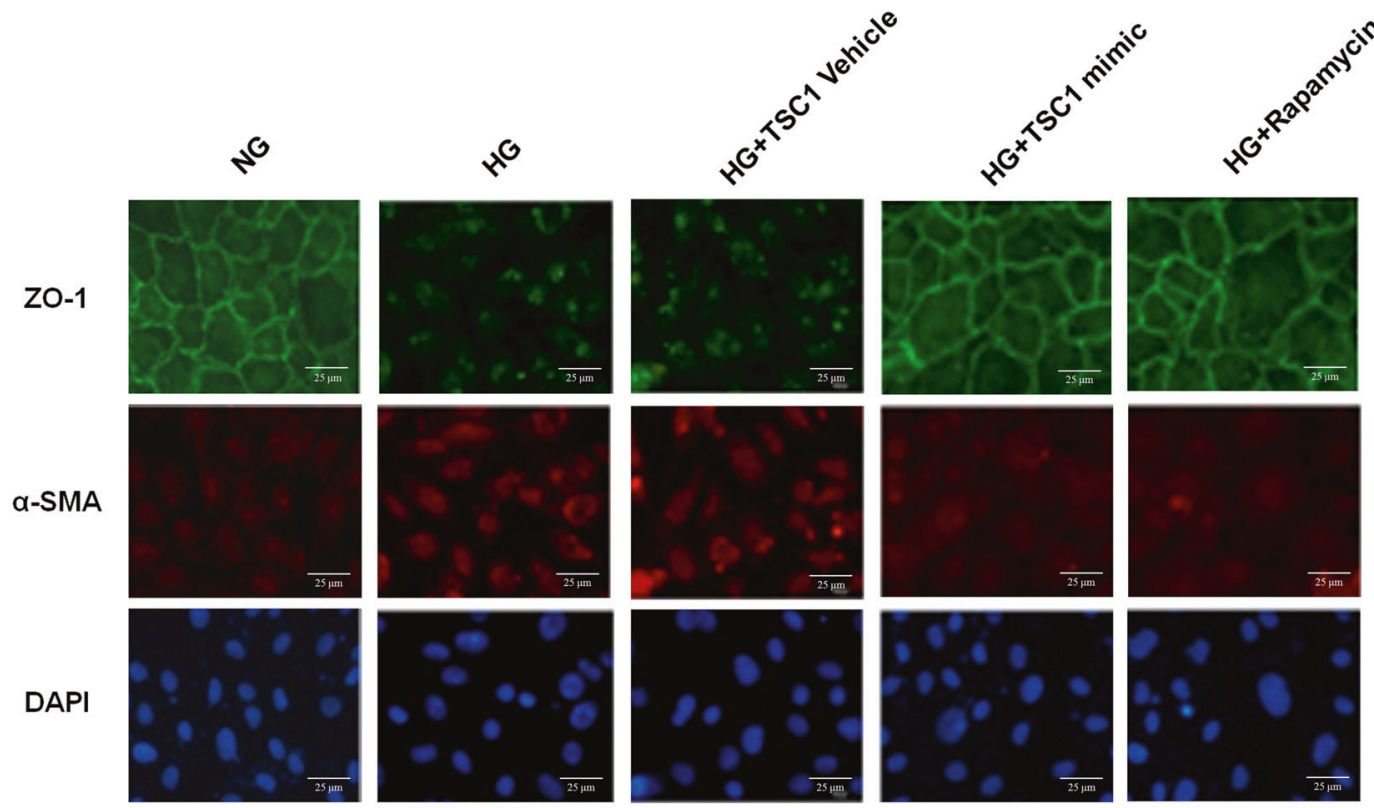

Merge
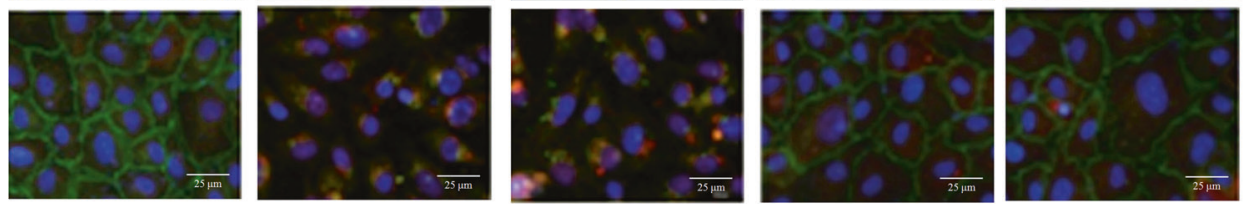

Fig. 4 Distribution and expressions of ZO-1 and $\alpha$-SMA in HK-2 cells by immunofluorescence. Bar $=25 \mu \mathrm{m}$

a

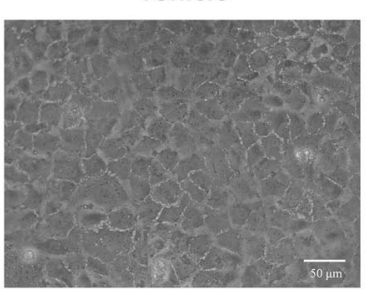

TSC1 ShRNA

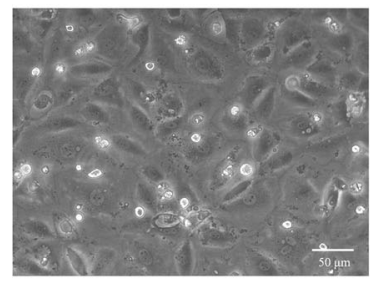

b

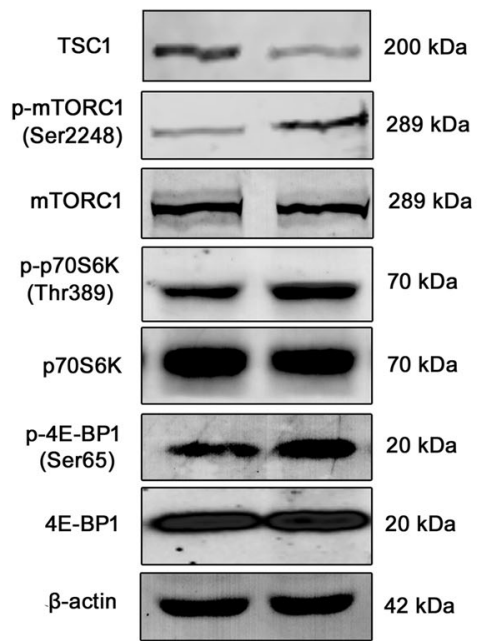

C
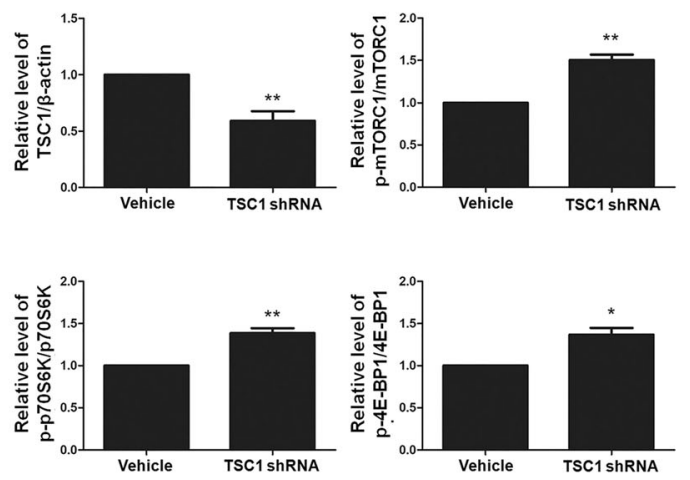

Fig. 5 Effect of TSC1 silencing on mTOR signaling of normal glucose-cultured HK-2 cells. a Effects of TSC1 shRNA stimulation on the changes of HK-2 cells morphology (magnification, $\times 400$ ). b The expression of TSC1, p-mTOR, mTOR, p-p70S6K, p70S6K, p-4E-BP1, and 4E-BP1 in HK-2 cells through Western blotting. c Statistical analysis of TSC1 expression and relative phosphorylation levels of mTOR, p70S6K, and 4E-BP1 in HK-2 cells. Vehicle: cells treated with normal glucose $5.56 \mathrm{mM}+$ TSC1 vehicle plasmids for $48 \mathrm{~h}$; TSC1 shRNA: cells treated with normal glucose $5.56 \mathrm{mM}$ + TSC1 shRNA plasmids for $48 \mathrm{~h}$. Data are presented as the mean $\pm \mathrm{SEM}, n=3$. ${ }^{*} P<0.05,{ }^{* *} P<0.01$, compared with Vehicle. Bar $=50 \mu \mathrm{m}$ 
a

$\mathrm{Oh}$

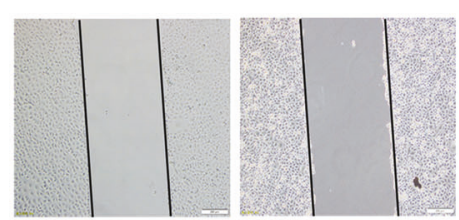

$12 \mathrm{~h}$
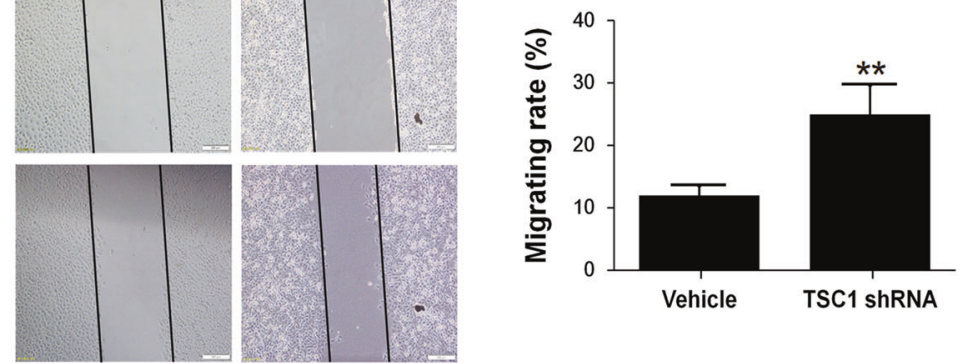

b
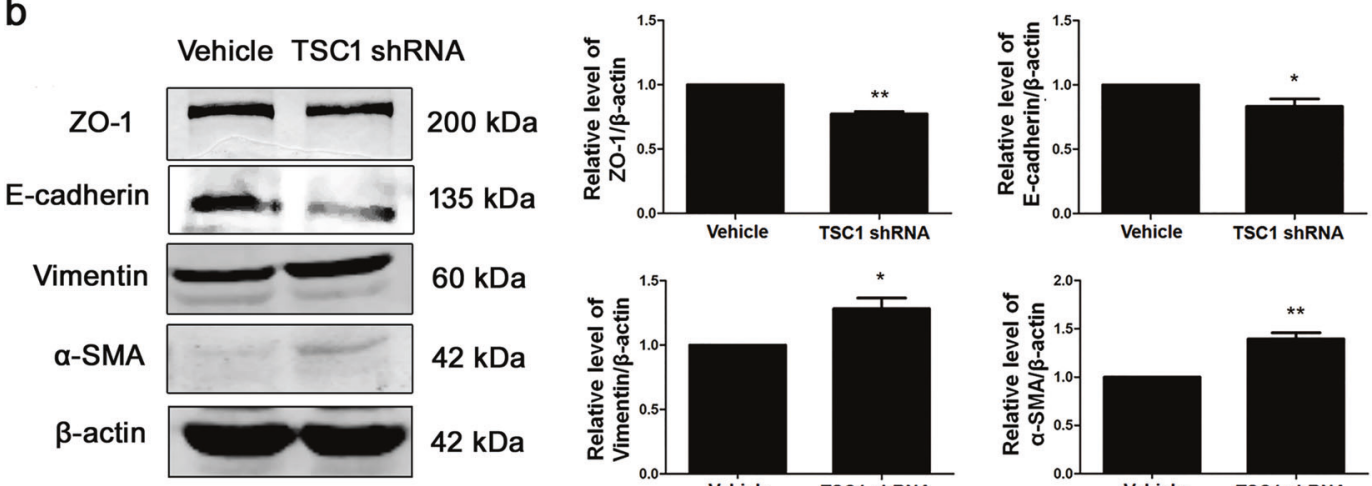

C
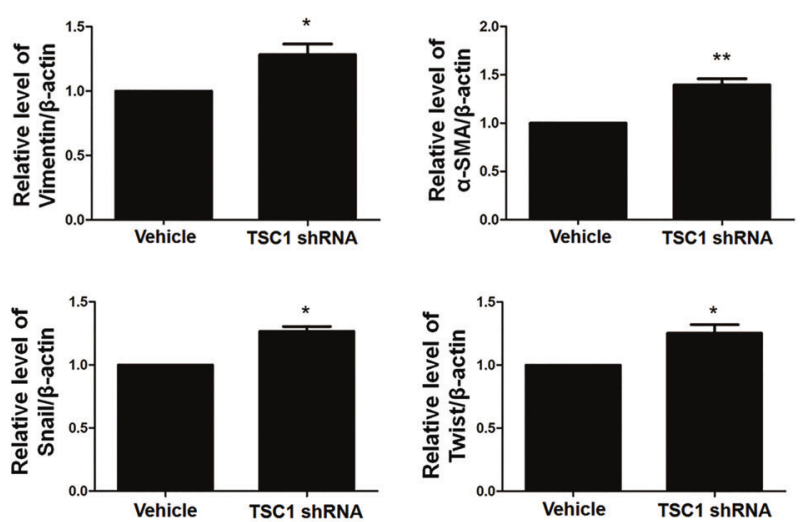

Twist

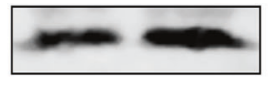

$21 \mathrm{kDa}$

$\beta$-actin

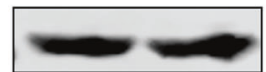

$42 \mathrm{kDa}$
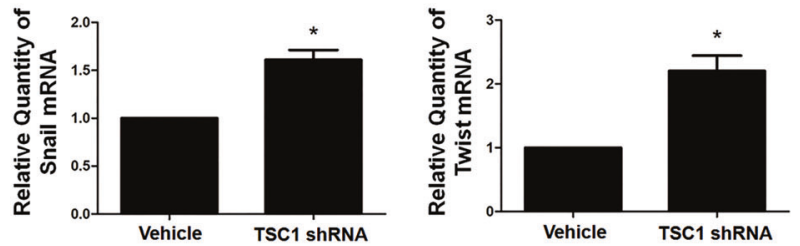

d
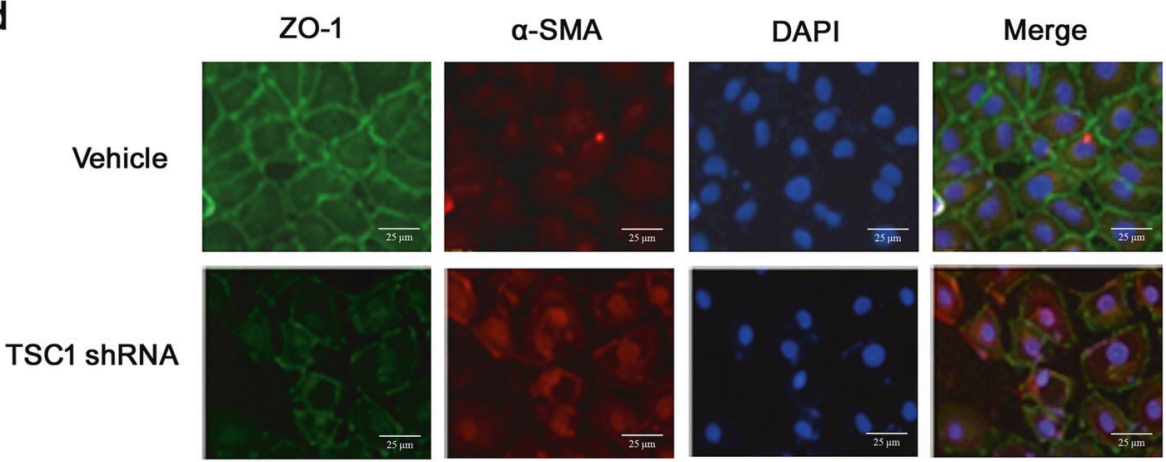

Fig. 6 Effect of TSC1 silencing on EMT of normal glucose-cultured HK-2 cells. a Invaded distances in HK-2 cells transfected with TSC1 shRNA plasmids by wound-healing assay. b Expression of ZO-1, E-cadherin, Vimentin, $\alpha$-SMA in HK-2 cells. c The protein and mRNA levels of two transcription factors (Snail and Twist) in normal glucose-cultured HK-2 cells by qRT-PCR. d Distribution and expressions of ZO- 1 and $\alpha$-SMA in HK-2 cells by immunofluorescence (bar $=25 \mu \mathrm{m}$ ). Vehicle: cells treated with normal glucose $5.56 \mathrm{mM}+\mathrm{TSC} 1$ vehicle plasmids for $48 \mathrm{~h}$; TSC1 shRNA: cells treated with normal glucose $5.56 \mathrm{mM}+\mathrm{TSC} 1$ shRNA plasmids for $48 \mathrm{~h}$. Data are presented as the mean \pm SEM, $n=3$. ${ }^{*} P<0.05,{ }^{* *} P<0.01$, compared with Vehicle 
a

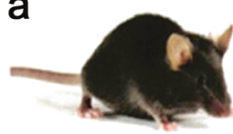

Ksp-Cre $\times$

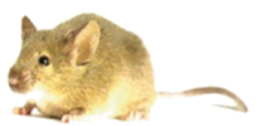

TSC1 fl/fl

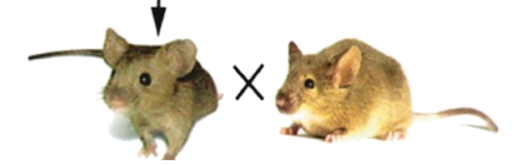

Ksp-Cre/TSC1+/-

TSC1 fl/fl

$\downarrow$

b
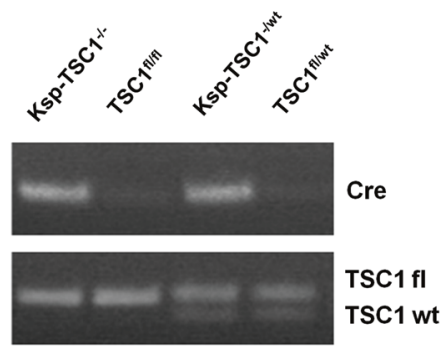

Ksp-Cre/TSC1-1-

C
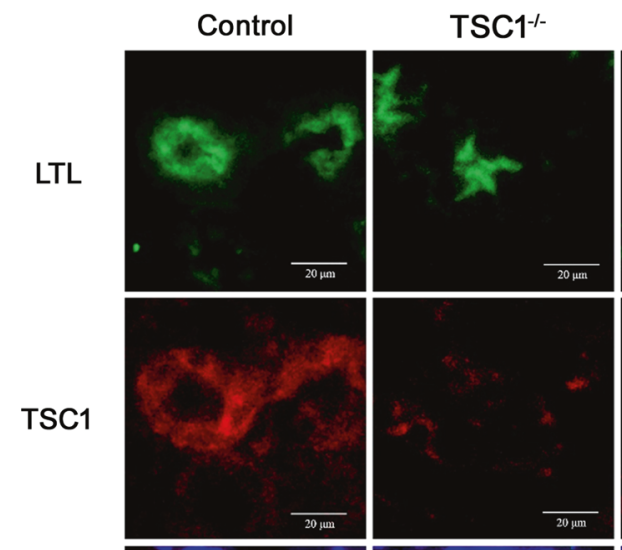

$\mathrm{TSC1}^{-1-+R a p}$
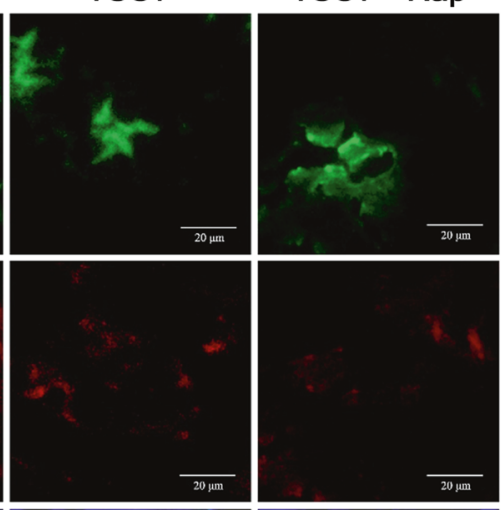

Merge
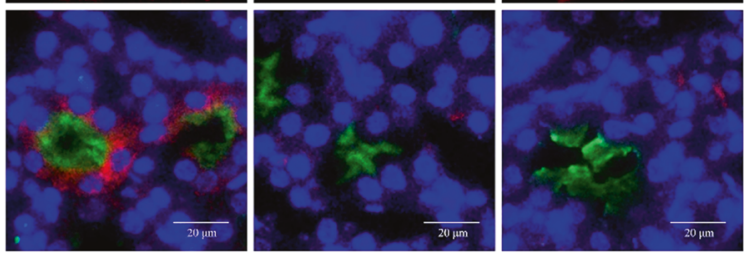

Fig. 7 The origin and identification of $\mathrm{TSC}^{-1-}$ mice. a Strategy for generating mice with tubules-specific deletion of TSC1. b Genotyping of the mice by PCR analysis of genomic DNA. c Expression of TSC $1^{-1-}$ mice by immunofluorescence (bar $\left.=20 \mu \mathrm{m}\right)$. LTL: fluorescein-labeled Lotus Tetragonolobus Lectin. LTL is specifically expressed in the tubules of kidney

\begin{tabular}{|c|c|c|c|c|c|c|}
\hline $\mathrm{TSC}^{\mathrm{fl} / \mathrm{fl}}, \mathrm{Cre}^{-1-}$ & $30.21 \pm 1.28$ & $9.81 \pm 0.47$ & $4.27 \pm 0.44$ & $33.23 \pm 1.86$ & $4.42 \pm 0.58$ & $248.66 \pm 28.74$ \\
\hline $\mathrm{TSC}_{1}{ }^{-1-}$ & $26.19 \pm 2.30^{*}$ & $12.98 \pm 0.50^{* *}$ & $4.52 \pm 0.35$ & $57.29 \pm 5.56^{* *}$ & $6.45 \pm 0.77^{* *}$ & $533.48 \pm 117.83^{*}$ \\
\hline $\mathrm{TSC} 1^{-1-}+$ Rap & $23.50 \pm 1.40^{\#}$ & $10.32 \pm 0.78^{\#}$ & $4.36 \pm 0.49$ & $38.67 \pm 8.56^{\# \#}$ & $5.04 \pm 0.62^{\#}$ & $269.26 \pm 58.13^{\# \#}$ \\
\hline$d b / d b+$ LV-TSC 1 & $41.18 \pm 3.55$ & $9.12 \pm 0.47^{\boldsymbol{\Delta}}$ & $20.31 \pm 2.21$ & $54.27 \pm 4.14^{\boldsymbol{\Lambda}}$ & $6.39 \pm 0.55$ & $384.13 \pm 41.51 \Delta$ \\
\hline
\end{tabular}

Data are presented as the mean \pm SEM, $n=8 .{ }^{*} P<0.05,{ }^{* *} P<0.01$, compared with control $\left(\mathrm{TSC}^{\mathrm{f} / \mathrm{fl}}, \mathrm{Cre}^{-/-}\right)$; ${ }^{\#} P<0.05$, ${ }^{\# \#} P<0.01$, compared with $\mathrm{TSC} 1^{-/-}$; ${ }^{\Delta} P<0.05,{ }^{\Delta \Delta} P<0.01$, compared with $d b / m$ mice; $\Delta_{P<0.05}$, compared with $d b / d b$ mice

expression of collagen IV and laminin in the renal cortex, particularly in the tubular basement membrane and tubular interstitium, when compared with the normal group. These alterations in diabetic kidneys were ameliorated to near normalcy after treatments with rapamycin. Moreover, compared with $d b / d b$ mice, lentiviral vector with TSC1-transfected $d b / d b$ mice reduced collagen IV and laminin accumulation in these regions (Fig. $8 c, d$ ). These results indicated that the excessive expression of collagen in the renal cortex of $d b / d b$ mice was inhibited by TSC1, thereby reducing the degree of renal fibrosis. 

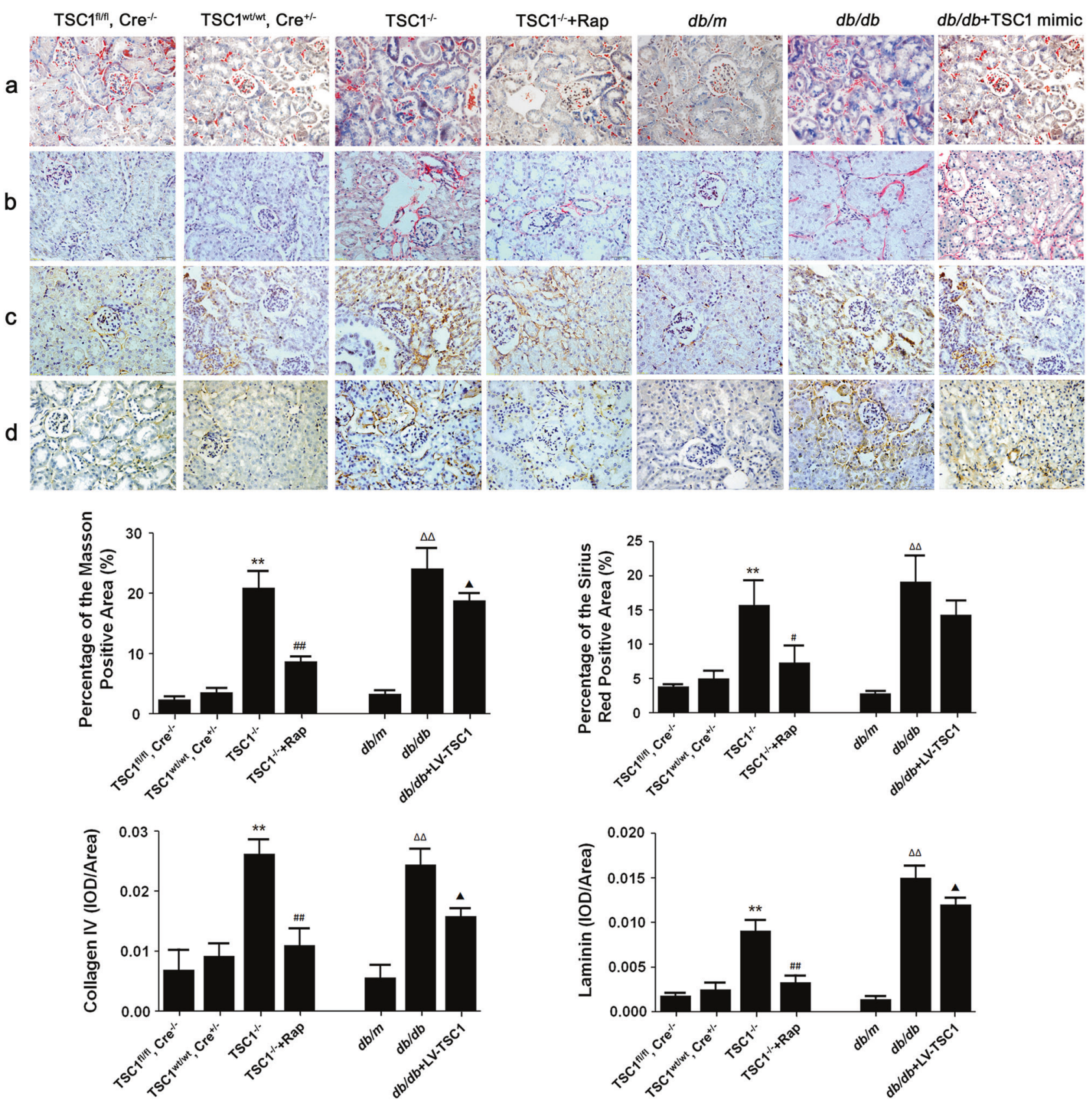

Fig. 8 Effect of TSC1 on kidney interstitial fibrosis. a Masson staining of renal cortex sections of mice. b Sirius Red staining of renal cortex sections of mice. c Collagen IV expression in renal cortex of mice through immunohistochemistry. $\mathbf{d}$ Laminin expression in renal cortex of mice through immunohistochemistry. Images $\mathbf{a}, \mathbf{b}, \mathbf{c}$, and $\mathbf{d}$ are representative staining images (magnification, $\times 40$ ). Data are presented as the mean \pm SEM, $n=6$. ${ }^{* *} P<0.01$, compared with control; ${ }^{\#} P<0.05$, ${ }^{\# \#} P<0.01$, compared with TSC ${ }^{-/-}$; ${ }^{\Delta \Delta} P<0.01$, compared with $d b / m$ mice; $\boldsymbol{\Delta}_{P}<0.05$, compared with $d b / d b$ mice

Effects of TSC1 on EMT in renal cortex in $\mathrm{TSC}^{-1-}$ mice and $d b / d b$ mice

To investigate the effect of TSC1 on the MTORC1 pathway in the renal cortex, the expression of mTORC1, p70S6K, and 4E-BP1 phosphorylation was examined in $\mathrm{TSC}^{-1-}$ mice. Compared with the normal groups ( $\mathrm{TSC}^{\mathrm{fl} / \mathrm{fl}}, \mathrm{Cre}^{-/-}$and $\left.\mathrm{TSC}^{\mathrm{wt} / \mathrm{wt}}, \mathrm{Cre}^{+--}\right)$, the expression of TSC 1 was decreased in $\mathrm{TSC}^{-1-}$ mice and treatment with rapamycin group. As expected, the phosphorylation of mTORC 1 and its downstream proteins, p70S6K and 4E-BP1, were significantly elevated, while treatment with rapamycin significantly inhibited mTORC1, p70S6K, and 4E-BP1 phosphorylation in $\mathrm{TSC}^{-1-}$ mice (Fig. 9). Western blotting was carried out to confirm the protein expression of TSC1 and to evaluate the transfection efficiency of TSC1 in $d b / d b$ mice. As shown in Fig. 9, the protein expression of TSC1 was significantly decreased in $d b / d b$ mice compared to $d b / m$ mice. Transfection of TSC1 successfully increased TSC1 protein levels and markedly decreased mTORC1 and p70S6K phosphorylation in the kidneys of $d b / d b$ mice. The above results suggested that TSC1 can inhibit mTORC1 signaling.

The process of EMT in renal tubular epithelial cells is an early process of renal fibrosis. To further confirm the effect of TSC1 inactivation on EMT in the renal cortex in $\mathrm{TST}^{-1-}$ mice, the expression of EMT marker protein was examined. Compared with the control group, the expression of ZO-1 and E-cadherin 

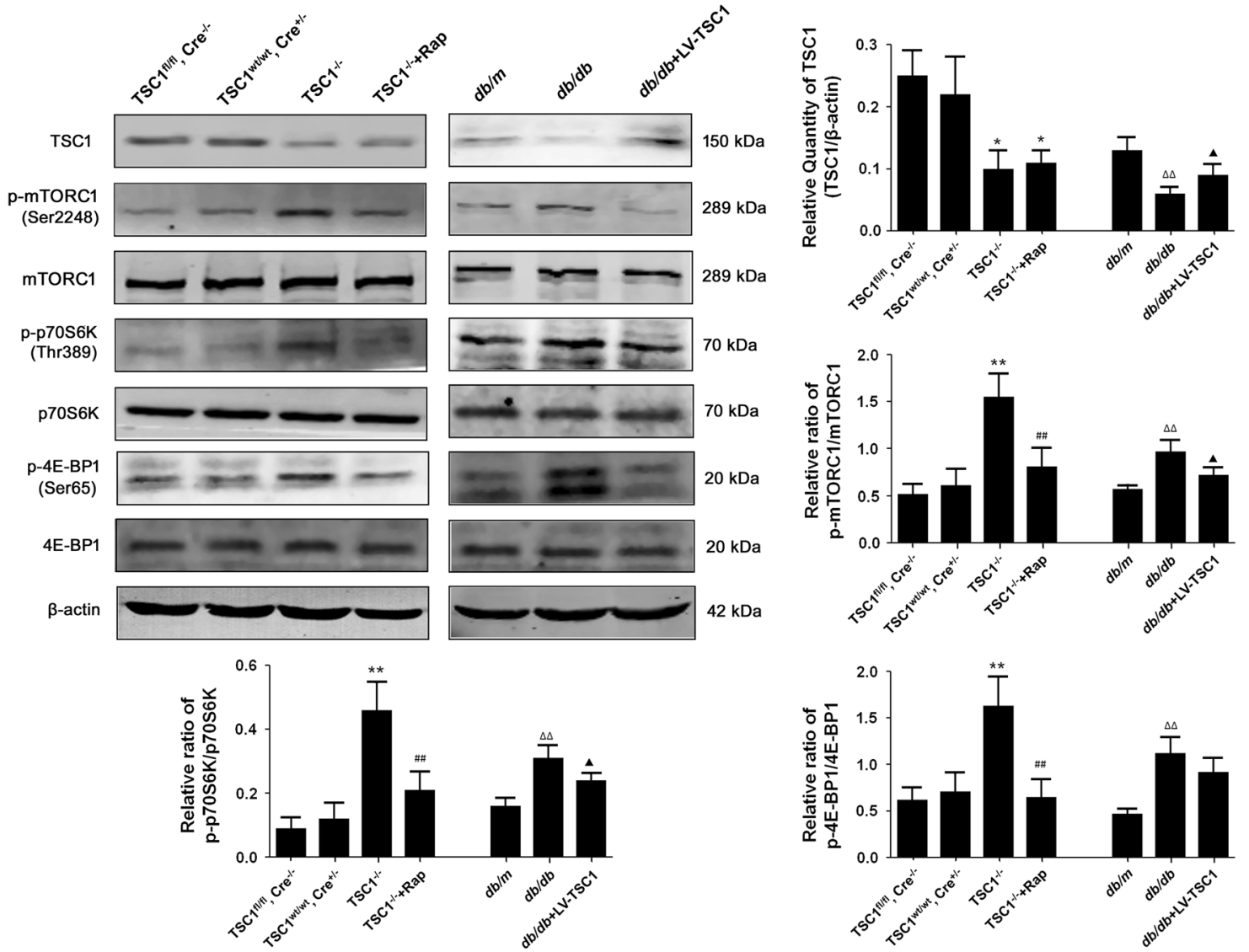

Fig. 9 Effect of TSC1 on mTORC1 signaling in TSC1 ${ }^{-1-}$ mice and $d b / d b$ mice. The expression of phosphorylation of TSC1, mTORC1, p70S6K, and 4E-BP1 levels in renal cortex of mice. Data are presented as the mean $\pm \mathrm{SEM}, n=6 .{ }^{*} P<0.05,{ }^{*} P<0.01$, compared with control; ${ }^{\# \#} P<0.01$, compared with $\mathrm{TSC}^{-1-} ;{ }^{\Delta \Delta} P<0.01$, compared with $\mathrm{db} / \mathrm{m}$ mice; $\boldsymbol{\Delta}_{P<0.05}$, compared with $\mathrm{db} / \mathrm{db}$ mice

in $\mathrm{TSC}^{-1-}$ mice was downregulated. In contrast, the expression of Vimentin and a-SMA was upregulated. Meanwhile, the expression of the EMT marker protein was also detected in $\mathrm{db} / \mathrm{m}$ mice and $d b / d b$ mice. Compared with $d b / m$ mice, the expression of ZO-1 and E-cadherin was significantly decreased in $d b / d b$ mice, while the expression of Vimentin and a-SMA was increased. Treatment with rapamycin or overexpression of TSC1 could effectively reverse the reduction of ZO-1 and E-cadherin and decrease the expression of Vimentin and a-SMA, respectively (Fig. 10a).

Moreover, to investigate the roles of transcription factors (Snail and Twist) in the renal cortex of mice, we examined the protein expression of these transcriptional repressors as well as mRNA levels. The results showed that the expression of Snail and Twist proteins and the mRNA levels were significantly increased in the renal cortex of $\mathrm{TSC}^{-1-}$ mice and $d b / d b$ mice compared with the normal group. Rapamycin blocked the high levels of two transcription factor proteins and mRNAs in $\mathrm{TSC}^{-1-}$ mice. However, TSC1-transinfected $d b / d b$ mice revealed a reduction of Snail protein levels in the renal cortex homogenate, while the protein expression of Twist erratically changed (Fig. 10b). The above results indicated that inactivation of TSC1 could promote EMT.

\section{DISCUSSION}

TSC is a genetic disorder linked to mutations of either the TSC1 or TSC2 gene, which produces TSC1-TSC2 to form a functional complex that negatively regulates mTOR signaling [9, 20]. Loss of function of either TSC1 or TSC2 will cause tumor formation in the heart, lung, brain, and kidney [21, 22]. Recent studies have demonstrated that inactivation of TSC1 or TSC2 in mesodermderived cells could cause polycystic kidney lesions and increase cell proliferation and tubular epithelial hyperplasia [23, 24]. Renal interstitial fibrosis is the critical pathological process in the development of DN, which culminates in the functional decline of the kidney [3]. However, whether dysfunction of the TSC/mTOR pathway induces renal interstitial fibrosis under high glucose and hyperglycemia conditions is not clear. To elucidate the consequences of TSC inactivation in renal tubular epithelial cells, we crossed TSC1-floxed mice with $\mathrm{Ksp}-\mathrm{Cre}$ transgenic mice to generate tubule-specific TSC1 knockout mice ( $\mathrm{TSC}^{-/-}$mice). $\mathrm{TSC}^{-1-}$ mice exhibited similar $\mathrm{Cr}, \mathrm{BUN}$, and total mAlb levels compared with $d b / d b$ controls, suggesting that TSC1 inactivation could lead to a decline in renal function. To further evaluate the effect of $\mathrm{TSC} 1$ on renal function in $\mathrm{DN}, d b / d b$ mice were transinfected with lentiviral vector with TSC1 by tail vein injection. We found that treatment with TSC1 improved the renal function of $d b / d b$ mice. In addition, to observe the extent of kidney fibrosis, we detected the excessive deposition of collagen by Masson and Sirius Red stainings in each group. Cumulative collagen was detected in the glomeruli, tubular basement membrane, and kidney interstitial areas of the $\mathrm{TSC}^{-1-}$ mice and $d b / d b$ mice. Collagen and laminin are components of the ECM. To reflect the severity of renal fibrosis, we detected the generation of collagens and laminin in each group. Collagens, particularly type IV collagen, and laminin were accumulated in glomerular and renal interstitial regions in the renal cortex of $\mathrm{TSC}^{-1-}$ and $d b / d b$ mice. Treatment with rapamycin or overexpression of TSC1 could effectively reverse the elevated deposition of collagen. These results 
a

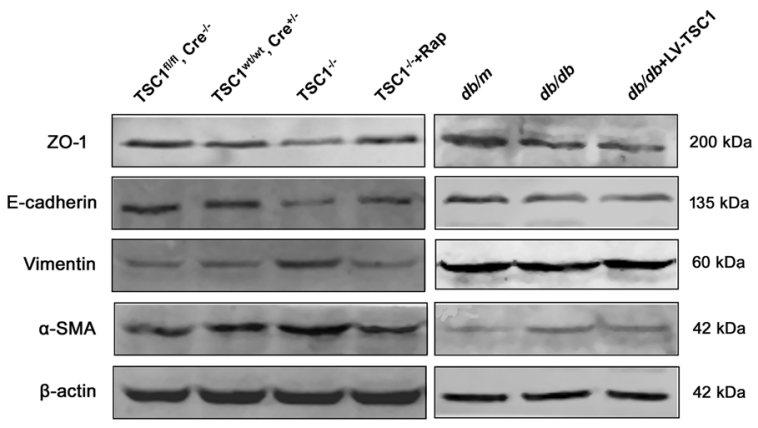

b

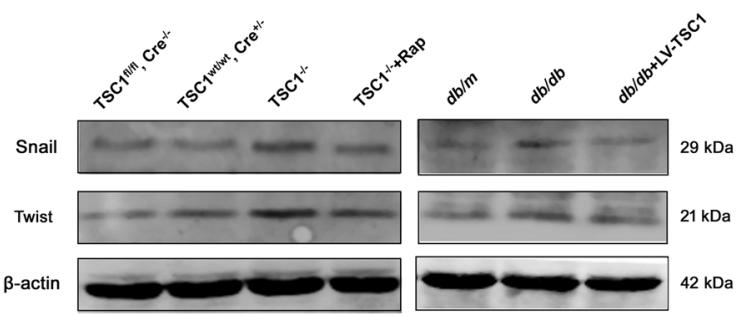

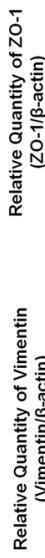
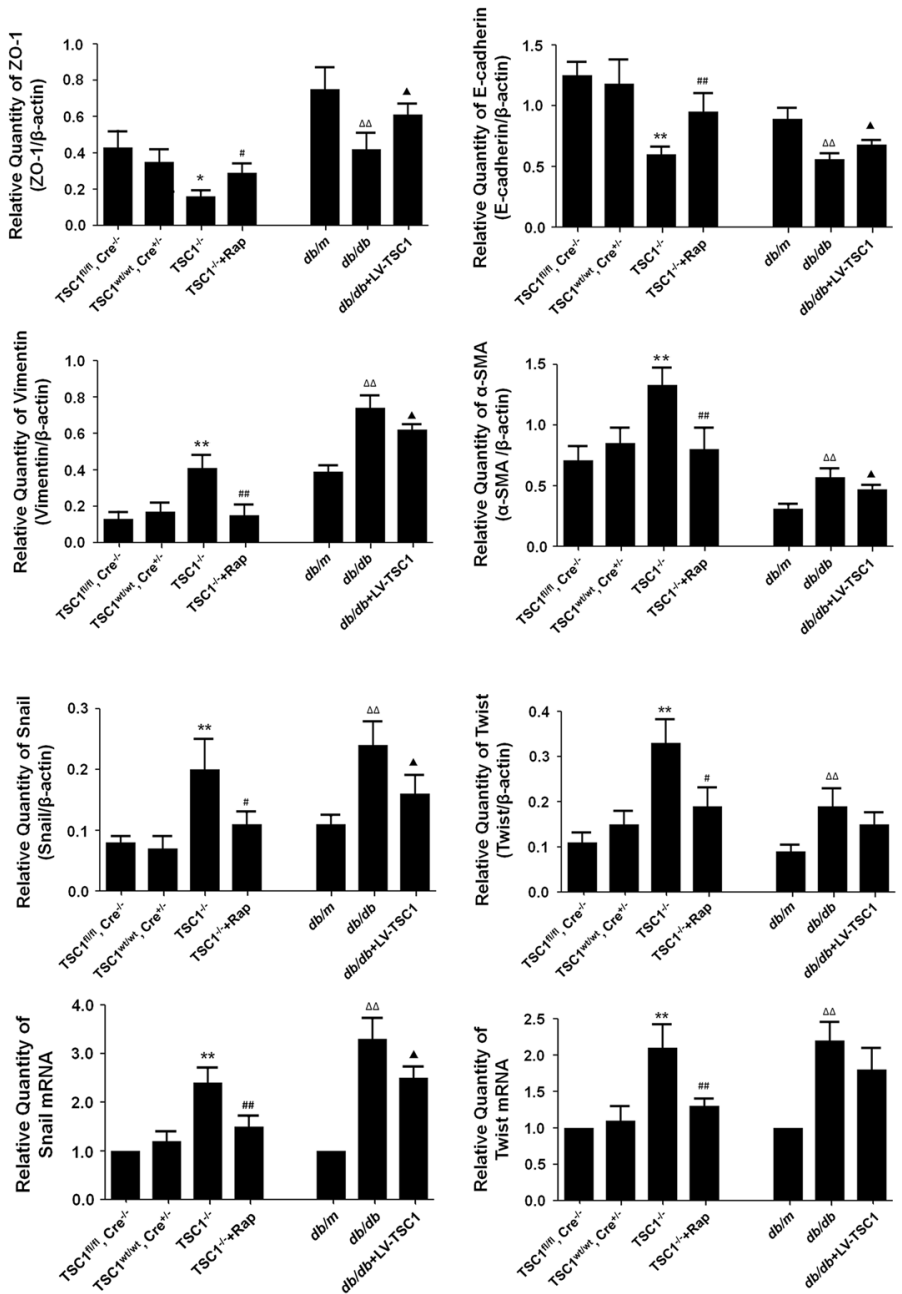

Fig. 10 Effect of TSC1 on EMT in TSC1 ${ }^{-1-}$ mice and $d b / d b$ mice. a Expression of ZO-1, E-cadherin, Vimentin, and $\alpha$-SMA in renal cortex of mice. b Expression of Snail and Twist in renal cortex of mice. Data are presented as the mean \pm SEM, $n=6$. ${ }^{*} P<0.05,{ }^{* * *} P<0.01$, compared with control; ${ }^{\#} P<0.05$, ${ }^{\# \#} P<0.01$, compared with TSC1 ${ }^{-1-} ;{ }^{\Delta \Delta} P<0.01$, compared with $d b / m$ mice; $\Delta_{P}<0.05$, compared with $d b / d b$ mice

indicated that TSC1 inactivation may be one of the important inducers of the decline in renal function and grievous renal fibrosis, and it showed similar pathological characteristics to $d b /$ $d b$ mice.

The EMT of renal tubular epithelial cells in diabetic patients is the early onset factor of renal interstitial fibrosis $[25,26]$. In this process, renal tubular epithelial cells are characterized by loss of epithelial proteins, including E-cadherin and ZO-1, and acquire the expression of more mesenchymal markers, such as a-SMA and Vimentin [5]. Changes in the expression of these proteins are generally accompanied by morphological changes from the cubic shape to the fibroblastoid appearance and enhancement of cell invasion and migration. A series of studies reported that TSC inactivation induced EMT through various factors and mechanisms. TSC1 regulates TGF$\beta$-induced Smad2/3 phosphorylation and target gene expression and controls TGF- $\beta$-induced growth arrest and EMT in HeLa cells [14]. In TSC2 ${ }^{-1-}$ cells, increased Src kinase activation can inhibit Ecadherin expression by upregulating the expression of Snail. Consequently, cells deficient in TSC2 are less adhesive and undergo EMT [27]. In our study, the treatment of HK-2 cells with HG for $72 \mathrm{~h}$ induced EMT as characterized by the loss of E-cadherin and ZO-1 and the de novo expression of a-SMA and Vimentin. In parallel with these in vitro results, the research showed that the expression of $\mathrm{E}$ cadherin and ZO-1 decreased whereas the expression of a-SMA and Vimentin increased in the renal cortex of $d b / d b$ mice. Furthermore, a wound-healing assay also confirmed that $\mathrm{HG}$ induced the migration in HK-2 cells. To further assess the effect of TSC1 on HG-induced EMT, HK-2 cells were transfected with a TSC1 mimic. We found that TSC1 overexpression significantly upregulated the expression of E-cadherin and ZO-1, decreased the expression of aSMA and Vimentin, and prevented the HG-induced migration of HK-2 cells. Transcriptional repressors Snail and Twist are also EMT markers [28, 29]. TSC1 overexpression notably decreased the expression of Snail and Twist. Similar to HG treatment, TSC1 siRNA also promoted the EMT of HK-2 cells. These phenomena were also observed in the renal cortex of $\mathrm{TSC}^{-1-}$ mice and TSC1transinfected $d b / d b$ mice. These results revealed that the development of renal tubular EMT is due, in part, to the inactivation of TSC1 under HG conditions, which leads to renal fibrosis.

Previous studies have shown that loss-of-function of either TSC1 or TSC2 can negatively regulate $\mathrm{mTORC} 1$ signaling and lead to hyperactivation of the mTORC1 signaling pathway [5]. mTORC1 is a serine/threonine protein kinase and a target of downstream TSC, which regulates many basic functions of cells by regulating the two major effectors of the downstream P70S6K and 4E-BP1 [9]. Growing evidence has proven that the abnormal activation of mTORC $1 /$ p70S6K signaling has been implicated in the pathogenesis of DN, including glomerular hypertrophy, podocyte dysfunction, and renal fibrosis $[30,31]$, and the inhibition of mTORC 1 with rapamycin attenuates the morphological and functional disorders 
of diabetic kidneys [11, 32]. Our previous studies also confirmed that quercetin and Ginkgo biloba leaf extract alleviated the EMT of HK-2 cells cultured under HG and renal fibrosis in diabetic rats through the inhibition of the mTORC1 signaling pathway [33]. In the present study, under the stimulation of $\mathrm{HG}$, the expression of TSC1 significantly decreased, whereas the phosphorylation rate of mTORC1 and the phosphorylation of its downstream effector proteins p70S6K and 4E-BP1 significantly increased. Transfected with the TSC1 shRNA plasmid at NG concentrations and the changes in the phosphorylation levels of mTORC1, p70S6K, and 4E-BP1 were similar to those in HG conditions. In contrast, transfection of cells with TSC1 mimic strikingly inhibited phosphorylation of mTORC1, p70S6K, and 4E-BP1 in HG-induced HK-2 cells. Similar to the results obtained in vitro, the in vivo study showed a decrease in TSC1 expression in the renal cortex, which subsequently increased the expression of p-mTORC1, p-p70S6K, and $\mathrm{p}-4 \mathrm{E}-\mathrm{BP} 1$ in $d b / d b$ mice and $\mathrm{TSC}^{-1-}$ mice. Transfection of TSC1 markedly decreased mTORC1 and p70S6K phosphorylation in the kidneys of $d b / d b$ mice. Accordingly, we suggest that TSC1 inactivation could activate the mTORC1 pathway in HG conditions.

\section{CONCLUSION}

In summary, our studies provide experimental evidence that TSC1 plays a key role in HG-induced EMT in renal tubular epithelial cells in DN. An HG concentration induces TSC1 inactivation, which stimulates the activation of the mTORC1 signaling pathway, causing the increased expression of Snail and Twist. As transcriptional factors, Snail and Twist reduce the expression of E-cadherin and ZO-1, which promote the EMT and accelerate the pathological process of renal fibrosis in DN. This process may be one of the molecular mechanisms underlying the progression of renal fibrosis.

\section{ACKNOWLEDGEMENTS}

The work was supported by the National Natural Science Foundation of China (No. 81473257, 81400741), the Qing Lan project, the Natural Science Foundation of Jiangsu Province (No. BK20151155), the "333" Foundation of Jiangsu Province (No. BRA2015329), the Key Natural Science Foundation of Jiangsu Higher Education Institutions of China (No. 15KJA310005), the Jiangsu Overseas Research \& Training Program for University Young \& Middle-aged Teachers and Presidents, and the Priority Academic Program Development of Jiangsu Higher Education Institutions (PAPD).

\section{AUTHOR CONTRIBUTIONS}

$X X Y$ designed and supervised the study and revised the paper; QL, YBC, HY, and WWW performed most of the experiments; $C C L$ and LW performed some of the experiments and analyzed part of the data; JW made the figures; LD purchased the reagents.

\section{ADDITIONAL INFORMATION}

Competing interests: The authors declare no competing interests.

\section{REFERENCES}

1. Rossing P. Diabetic nephropathy: worldwide epidemic and effects of current treatment on natural history. Curr Diab Rep. 2006;6:479-83.

2. Kanwar YS, Sun L, Xie P, Liu FY, Chen S. A glimpse of various pathogenetic mechanisms of diabetic nephropathy. Annu Rev Pathol. 2011;6:395-423.

3. Simonson MS. Phenotypic transitions and fibrosis in diabetic nephropathy. Kidney Int. 2007;71:846-54.

4. Kalluri R, Neilson EG. Epithelial-mesenchymal transition and its implications for fibrosis. J Clin Invest. 2003;112:1776-84.

5. Liu Y. New insights into epithelial-mesenchymal transition in kidney fibrosis. J Am Soc Nephrol. 2010;21:212-22.
6. Switon K, Kotulska K, Janusz-Kaminska A, Zmorzynska J, Jaworski J. Tuberous sclerosis complex: from molecular biology to novel therapeutic approaches. IUBMB Life. 2016;68:955-62.

7. Inoki K. Role of TSC-mTOR pathway in diabetic nephropathy. Diabetes Res Clin Pract. 2008;82(Suppl 1):S59-62.

8. Hasbani DM, Crino PB. Tuberous sclerosis complex. Handb Clin Neurol. 2018;148:813-22.

9. Inoki K, Li Y, Zhu T, Wu J, Guan KL. TSC2 is phosphorylated and inhibited by Akt and suppresses mTOR signalling. Nat Cell Biol. 2002;4:648-57.

10. Ma L, Chen Z, Erdjument-Bromage $H$, Tempst $P$, Pandolfi PP. Phosphorylation and functional inactivation of TSC2 by Erk implications for tuberous sclerosis and cancer pathogenesis. Cell. 2005;121:179-93.

11. Lee $\mathrm{CH}$, Inoki $\mathrm{K}$, Guan $\mathrm{KL}$. mTOR pathway as a target in tissue hypertrophy. Annu Rev Pharm Toxicol. 2007;47:443-67.

12. Inoki K, Zhu T, Guan KL. TSC2 mediates cellular energy response to control cell growth and survival. Cell. 2003;115:577-90.

13. Wataya-Kaneda M. Mammalian target of rapamycin and tuberous sclerosis complex. J Dermatol Sci. 2015;79:93-100.

14. Thien A, Prentzell MT, Holzwarth B, Kläsener K, Kuper I, Boehlke C, et al. TSC1 activates TGF- $\beta$-Smad2/3 signaling in growth arrest and epithelial-tomesenchymal transition. Dev Cell. 2015;32:617-30.

15. Barnes EA, Kenerson HL, Jiang X, Yeung RS. Tuberin regulates E-cadherin localization: implications in epithelial-mesenchymal transition. Am J Pathol. 2010;177:1765-78.

16. Habib SL, Yadav M, Tizani S, Bhandari B, Valente AJ. Tuberin inhibits production of the matrix protein fibronectin in diabetes. J Am Soc Nephrol. 2012;23:1652-62.

17. Yao Y, Wang J, Yoshida S, Nada S, Okada M, Inoki K. Role of ragulator in the regulation of mechanistic target of rapamycin signaling in podocytes and glomerular function. J Am Soc Nephrol. 2016;27:3653-65.

18. Zhang Z, Li BY, Li XL, Cheng M, Yu F, Lu WD, et al. Proteomic analysis of kidney and protective effects of grape seed procyanidin $\mathrm{B} 2$ in $d b / d b$ mice indicate MFGE8 as a key molecule in the development of diabetic nephropathy. Biochim Biophys Acta. 2013;1832:805-16.

19. Lu Q, Ji XJ, Zhou YX, Yao XQ, Liu YQ, Zhang F, et al. Quercetin inhibits the mTORC1/p70S6K signaling-mediated renal tubular epithelial-mesenchymal transition and renal fibrosis in diabetic nephropathy. Pharm Res. 2015. 99:237-47.

20. Kapoor A, Girard L, Lattouf JB, Pei Y, Rendon R, Card P, et al. Evolving strategies in the treatment of Tuberous Sclerosis Complex-associated Angiomyolipomas (TSCAML). Urology. 2016;89:19-26.

21. Randle SC. Tuberous sclerosis complex: a review. Pediatr Ann. 2017;46:e166-e171.

22. Leung AK, Robson WL. Tuberous sclerosis complex: a review. J Pediatr Health Care. 2007;21:108-14.

23. Ren S, Luo Y, Chen H, Warburton D, Lam HC, Wang LL, et al. Inactivation of Tsc2 in mesoderm-derived cells causes polycystic kidney lesions and impairs lung alveolarization. Am J Pathol. 2016;186:3261-72.

24. Zhou J, Brugarolas J, Parada LF. Loss of Tsc1, but not Pten, in renal tubular cells causes polycystic kidney disease by activating mTORC1. Hum Mol Genet. 2009;18:4428-41.

25. Carew RM, Wang B, Kantharidis P. The role of EMT in renal fibrosis. Cell Tissue Res. 2012;347:103-16.

26. Hills CE, Squires PE. The role of TGF- $\beta$ and epithelial-to mesenchymal transition in diabetic nephropathy. Cytokine Growth Factor Rev. 2011;22:131-9.

27. Tyryshkin A, Bhattacharya A, Eissa NT. SRC kinase is a novel therapeutic target in lymphangioleiomyomatosis. Cancer Res. 2014;74:1996-2005.

28. Wang Y, Shi J, Chai K, Ying X, Zhou BP. The role of Snail in EMT and tumorigenesis. Curr Cancer Drug Targets. 2013;13:963-72.

29. Ansieau S, Bastid J, Doreau A, Morel AP, Bouchet BP, Thomas C, et al. Induction of EMT by twist proteins as a collateral effect of tumor-promoting inactivation of premature senescence. Cancer Cell. 2008;14:79-89.

30. Inoki K, Mori H, Wang J, Suzuki T, Hong S, Yoshida S, et al. mTORC1 activation in podocytes is a critical step in the development of diabetic nephropathy in mice. J Clin Invest. 2011;121:2181-96.

31. Kajiwara M, Masuda S. Role of mTOR inhibitors in kidney disease. Int J Mol Sci. 2016;17:E975.

32. Chen JK, Chen J, Neilson EG, Harris RC. Role of mammalian target of rapamycin signaling in compensatory renal hypertrophy. J Am Soc Nephrol. 2005;16:1384-91.

33. Lu Q, Zuo WZ, Ji XJ, Zhou YX, Liu YQ, Yao XQ, et al. Ethanolic Ginkgo biloba leaf extract prevents renal fibrosis through Akt/mTOR signaling in diabetic nephropathy. Phytomedicine. 2015;22:1071-8. 